\title{
Academic Application of Good Cell Culture Practice for Induced Pluripotent Stem Cells
}

\author{
Julia Tigges', Kevin Bielec ${ }^{1}$, Gabriele Brockerhoff1, Barbara Hildebrandt2, Ulrike Hübenthal1, Julia Kapr', \\ Katharina Koch', Nadine Teichweyde', Dagmar Wieczorek², Andrea Rossil and Ellen Fritsche1,3 \\ ${ }^{1}$ IUF-Leibniz Research Institute for Environmental Medicine, Duesseldorf, Germany; ${ }^{2}$ Institute of Human Genetics, Medical Faculty, Heinrich-Heine- \\ University, Duesseldorf, Germany; ${ }^{3}$ Medical Faculty, Heinrich-Heine-University, Duesseldorf, Germany
}

\begin{abstract}
Human induced pluripotent stem cells (hiPSC) are a promising tool for replacing animal-based experiments. To warrant data reproducibility, quality-controlled research material is recommended. While the need for global harmonization of quality standards for stem cell banking centers, commercial providers, pre-clinical and clinical use of cells is well documented, there are no recommendations available for quality control of hiPSC in an academic research environment to date. To fill this gap, we here give an example of a quality-controlled, two-tiered banking process producing a fully characterized master cell bank (MCB) and partially characterized respective working cell banks (WCB). Characterization includes the study of morphology, mycoplasma contamination, cell line identity, karyotype stability, cell antigen expression and viability, gene expression, pluripotency, and post-thaw recovery. Costs of these procedures are calculated. We present the results of the proposed testing panel of two hiPSC MCBs and show that both fulfil the defined specifications regarding the above-mentioned characterization assays during and upon banking. In conclusion, we propose a panel of eight assays, which are practical and useful for an academic research laboratory working with hiPSCs. Meeting these proposed specifications ensures the quality of pluripotent stem cells throughout diverse experiments at moderate costs.
\end{abstract}

\section{Introduction}

The development of human induced pluripotent stem cells (hiPSCs; Takahashi et al., 2007) bears immense opportunities for basic research, toxicological screening efforts, and next generation human safety assessment (Pistollato et al., 2012; Fritsche et al., 2020). Human iPSCs have distinct advantages compared to human embryonic stem cells (hESC), including similar self-renewal and pluripotency capacity, while raising fewer ethical concerns regarding their derivation process (Fritsche et al., 2020). Especially during the last decade, the use of hiPSCs has become increasingly popular in basic research (Liu et al., 2020), which results in a need for standardized technologies for hiPSC applications to enable the comparison between various experiments and researchers from different laboratories (Maddah et al., 2014).

According to a Nature survey of over 1,500 researchers in 2016 , between $70 \%$ and $50 \%$ failed to reproduce another sci- entist's or even their own experiments, respectively (Baker and Penny, 2016; Miyakawa, 2020). Among the factors contributing to this reproducibility crisis are selective reporting, low statistical power, or poor analysis and experimental design (Baker and Penny, 2016). In addition, poor starting material - especially for hiPSC research - can be a severe source of irreproducibility (Stacey et al., 2013; Pamies et al., 2017). Therefore, already in 2013 "an urgent need" to establish routine screening methods for the characterization of quality-controlled stem cells was identified (Stacey et al., 2013; Crook et al., 2017).

While there is guidance available for Good In Vitro Methods Practices in general (OECD, 2018) or stem cell-based Good Cell Culture Practice specifically (Pamies et al., 2017, 2018, 2020), giving detailed insights into the broad subject of quality assurance (QA) and quality control (QC) of in vitro (stem cell-based) methods, these leave the average academic researcher with a plethora of QC assays, discussing pros and cons that might or
Received January 22, 2021: Accepted April 29, 2021;

Epub April 29, 2021; (C) The Authors, 2021.

ALTEX 38(4), 595-614. doi:10.14573/altex.2101221

Correspondence: Ellen Fritsche, PhD

IUF - Leibniz Research Institute for Environmental Medicine

Auf'm Hennekamp 50

40225 Duesseldorf, Germany

(Ellen.Fritsche@IUF-duesseldorf.de)
This is an Open Access article distributed under the terms of the Creative Commons Attribution 4.0 International license (http://creativecommons.org/licenses/by/4.0/) which permits unrestricted use, distribution and reproduction in any medium, provided the original work is appropriately cited. 
might not be of relevance to their specific needs. More specific guidelines exist that address the need for global harmonization of quality standards for stem cell banking centers and commercial providers (ISCBI, 2009; Ntai et al., 2017; Pamies et al., 2017) or for future pre-clinical and clinical use of cells (McNutt, 2014; Baghbaderani et al., 2015; Kim et al., 2017, 2019; Abbot et al., 2018; Sullivan et al., 2018). But to date no specific "hands on" guidelines are available for cell culture, banking and characterization of hiPSC that have been accessed from external sources such as commercial vendors or iPSC biobanks for use in an academic basic research environment (Li et al., 2015; Baker, 2016). It is certainly not feasible for hypothesis-driven academic research to perform the QC requirements of legal authorities, but undoubtedly also academic research benefits from applying some of the QC concepts developed for regulatory purposes (Dekant, 2016).

Uncertainties in the choice of QC procedures and their standardization as well as prima facie fears of high costs and demanding labor contribute to the fact that, despite their high importance for hiPSC research, QC assays are rarely standardized in academic laboratories (Lenz et al., 2015; Suter-Dick et al., 2015; Scudellari, 2016). However, two arguments clearly support the implementation of QC procedures into academic research: (i) costs for QC are negligible compared to the financial and reputational burden that might be incurred when years of research are in vain due to non-reproducibility of data (Suter-Dick et al., 2015) and (ii) the societal responsibility based on the public's financial investment into research (Munafò et al., 2017) not to mention the individual researcher's satisfaction gained from reproducible experiments.

The United States National Institutes of Health (NIH) already recognized the issue of reproducibility in (academic) cell culture studies in 2015 (NIH, 2015). Aspects identified as crucial for quality assurance were (hiPSC) cell line identity, genomic stability, pluripotency, and residual reprogramming factors. Implementing routine tests for such QC parameters into the stem cell community is facing a lack of consensus about standards, policies and practices, yet is necessary to ensure the highest quality and uniformity of stem cell lines (Yaffe et al., 2016).

We tackled this challenge by proposing a two-tiered hiPSC banking approach as recommended by the International Stem Cell Banking Initiative (ISCBI, 2009) and others (Coecke et al., 2005; Pistollato et al., 2012). This approach combines easy to apply characterization assays and QC release criteria for an hiPSC master cell bank (MCB) and a shortened testing scheme for second-tiered working cell banks (WCB). This two-tiered scheme of culturing, banking, and testing will ensure consistent quality and performance of hiPSCs employed for basic research (Fig. 1). We show that a selection of assays for hiPSC character- ization (Adler et al., 2007; Pistollato et al., 2012) is sufficient, feasible, and affordable to achieve reproducible cellular models in an academic setting that can subsequently serve as the basis for further test development.

\section{Materials and methods}

Cell culture and characterization assays were performed according to detailed standard operation procedures (SOPs) developed and implemented within our laboratory.

\subsection{Cell culture}

\subsubsection{Cell lines}

One vial of the hiPSC line IMR90-C4 was purchased (\#iPS(IMR)90-4-DL-01, WiCell, Madison, Wisconsin, USA), and the knock-in IMR90-C4 ACTB-2A-LifeAct-eGFP line (DU22; short Life-Act-eGFP) was generated using CRISPR/ Cas9 (Rossi et al., unpublished). IMR90-C4 were cultivated on laminin (LN) 521-coated 6-well plates (see 2.1.1.1) in iPSBrew medium (see 2.1.1.2) except for assay 5 (cell antigen expression), for which the cells were transitioned to Matrigel (MG) and mTeSR (see 2.1.2.4). Life-Act-eGFP were cultivated on MG-coated 6-well plates (see 2.1.1.1) in mTeSR1 medium (see 2.1.1.2).

\subsubsection{Coating of plates}

LN521: One vial of 5 mL LN521 (\#LN521-05; BioLamina AB, Sweden) was slowly thawed at $4{ }^{\circ} \mathrm{C}$ for approx. $45 \mathrm{~min}$ (solution should be transparent and clear without ice inside), aliquoted, and stored at $-20^{\circ} \mathrm{C}$ until further use. Coating: LN521 stock solution was thawed at $4^{\circ} \mathrm{C}$ as described above and diluted 1:20 in $\mathrm{PBS}^{(+/+)}$by pipetting LN521/PBS solution up and down 5 times. $1 \mathrm{~mL}$ of this working solution (resulting in $0.5 \mu \mathrm{g} / \mathrm{cm}^{2}$ ) was added per 6-well plate well, and it was ensured that the entire well surface was covered. Cell culture plates were sealed using Parafilm ${ }^{\circledR}$ to prevent evaporation and contamination and incubated at $4^{\circ} \mathrm{C}$ overnight. Coated plates can be used for up to 4 weeks. When plates were needed to seed cells, they were first equilibrated at RT for at least $15 \mathrm{~min}$. The remaining LN521/ PBS solution was aspirated and directly replaced with $2 \mathrm{~mL}$ of fresh hiPSC medium before cells were plated (see 2.1.2.3).

MG: One vial of MG (\#356231; Corning, USA; alternatively, \#354277 can be used) was thawed overnight on ice at $4^{\circ} \mathrm{C}$, and $1000 \mu \mathrm{L}$ pipette tips were precooled at $4^{\circ} \mathrm{C}$ overnight. Once MG was thawed, it was swirled to ensure that the material was evenly dispersed. MG was kept on ice during the whole procedure described and diluted $1: 1$

Abbreviations

$\mathrm{AB}$, antibody; aCGH, array comparative genomic hybridization; AFP, a-feto protein; D, day; d.o.p., depending on provider; EB, embryoid body; FISH, fluorescent in situ hybridization; FMO, fluorescence minus one, Fvs, fixable viability stain; hESC, human embryonic stem cells; hiPSC, human induced pluripotent stem cells; hPSC, human pluripotent stem cells; ISCBI, International Stem Cell Banking Initiative; kbs, kilobase pairs; LN, laminin; MCB, master cell bank; MG, Matrigel; N2, liquid nitrogen; n.a.c. no additional costs; NIH, National Institutes of Health; NS, novelty score; P, passage; PBS, phosphate-buffered saline; Pen/Strep, penicillin/streptomycin; PS, pluripotency score; p.t., post thawing; QA, quality assurance; QC, quality control; RT, room temperature; SMA, smooth muscle actin; SNP, single-nucleotide polymorphism; SOP, standard operation procedure; STR, short tandem repeat; TUBB3, $\beta$ (III) tubulin; WCB, working cell bank 


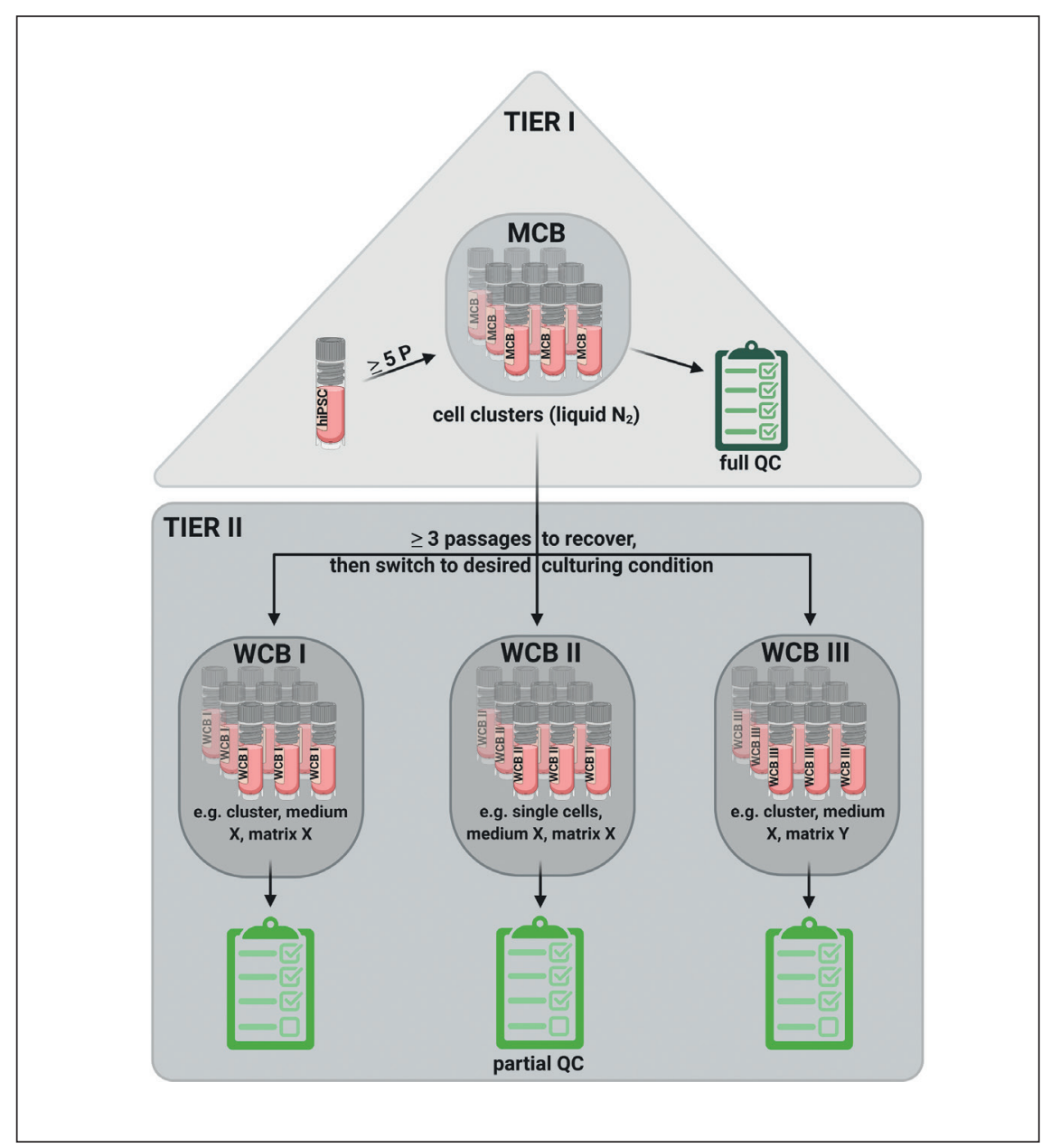

Fig. 1: Schematic illustration of the proposed two-tiered banking process In tier I, a vial of hiPSC is thawed, cultivated, and expanded for at least 5 passages $(P)$, and a Master Cell Bank (MCB) is prepared and stored in the vapor phase of liquid nitrogen $\left(\mathrm{N}_{2}\right)$. Full quality control (QC) of cells including all 8 proposed assays (see Tab. 4) must be performed at the point of freezing to ensure the quality of the cells at the time of freezing. In tier II, a vial of the MCB is thawed and cultivated for at least 3 passages under the respective conditions. Then cells are switched to desired culturing conditions, expanded, and Working Cell Banks (WCBs) are frozen in vapor phase of $\mathrm{N}_{2}$. One WCB is generated for each culturing condition needed for the respective project for which the cells are designated (e.g., single cells vs. clusters, different media, different matrices). Here only partial $\mathrm{QC}$ is performed.

with cold KnockOut ${ }^{\mathrm{TM}}$ DMEM (\#10829018; Thermo Fisher Scientific, USA). A precooled pipette tip was used to gently pipette the $\mathrm{MG}$ and ensure homogeneity. $0.5 \mathrm{~mL}$ aliquots of diluted MG were prepared using precooled pipette tips (tips need to be changed every time MG starts to clog at the end of the tip). MG aliquots were stored at $-20^{\circ} \mathrm{C}$ until further use. Coating: For coating of 6-well plates, one MG aliquot was placed into a class II biological safety cabinet, and $1 \mathrm{~mL}$ cold KnockOut ${ }^{\mathrm{TM}}$ DMEM medium was added on top of the still frozen MG and mixed by shaking and inverting of the tube. $13.5 \mathrm{~mL}$ KnockOut $^{\mathrm{TM}}$ DMEM were added using a $10 \mathrm{~mL}$ serological pipette, and the solution was mixed by pipetting up and down (trying to avoid air bubbles and ensuring that no pellets were left inside the tube). Then $1 \mathrm{~mL}$ of this working solution was added per 6-well plate well, and it was ensured that the entire well surface was covered (one aliquot should yield 14 wells). Cell culture plates were sealed using Parafilm ${ }^{\circledR}$ to prevent evaporation and contamination and were incubated at RT for $1 \mathrm{~h}$. After this, the coated plates were stored at $4^{\circ} \mathrm{C}$ and could be used for up to 2 weeks. When plates were needed to seed cells, they were first equilibrated at RT for at least $15 \mathrm{~min}$.
Then the MG solution was removed, and $1 \mathrm{~mL}$ KnockOut ${ }^{\mathrm{TM}}$ DMEM was added to each coated well for washing. KnockOut ${ }^{\mathrm{TM}}$ DMEM was aspirated and directly replaced by $2 \mathrm{~mL}$ of fresh medium before cells were plated.

\subsubsection{Cell culture media}

StemMACS ${ }^{\text {TM }}$ iPS-Brew XF medium (iPSC-Brew; \#130-104368; Miltenyi Biotech, Bergisch Gladbach, Germany): For iPSBrew medium preparation, the $10 \mathrm{~mL}$ vial of iPS-Brew 50x supplement and $5 \mathrm{~mL}$ of penicillin/streptomycin (Pen/Strep; \#P0607100; PAN Biotech, Aidenbach, Germany) were thawed at $4^{\circ} \mathrm{C}$ for approx. $2 \mathrm{~h}$ before combining them with one $500 \mathrm{~mL}$ bottle of iPS-Brew basal medium. Medium was mixed by shaking, aliquoted into labelled (name of medium, volume, expiration date and date of aliquoting) sterile $50 \mathrm{~mL}$ tubes and stored at $-20^{\circ} \mathrm{C}$ until further use. Aliquots were thawed at $4^{\circ} \mathrm{C}$ overnight when needed. mTeSR ${ }^{\mathrm{TM}} 1$ (mTeSR; 85850; STEMCELL Technologies Inc., Canada): For mTeSR medium preparation, $5 x$ supplement was thawed either overnight at $4^{\circ} \mathrm{C}$ or at RT and mixed thoroughly before adding it to $\mathrm{mTeSR}$ basal medium. $5 \mathrm{~mL}$ Pen/Strep was also added, and full medium was mixed well by shaking, aliquoted 


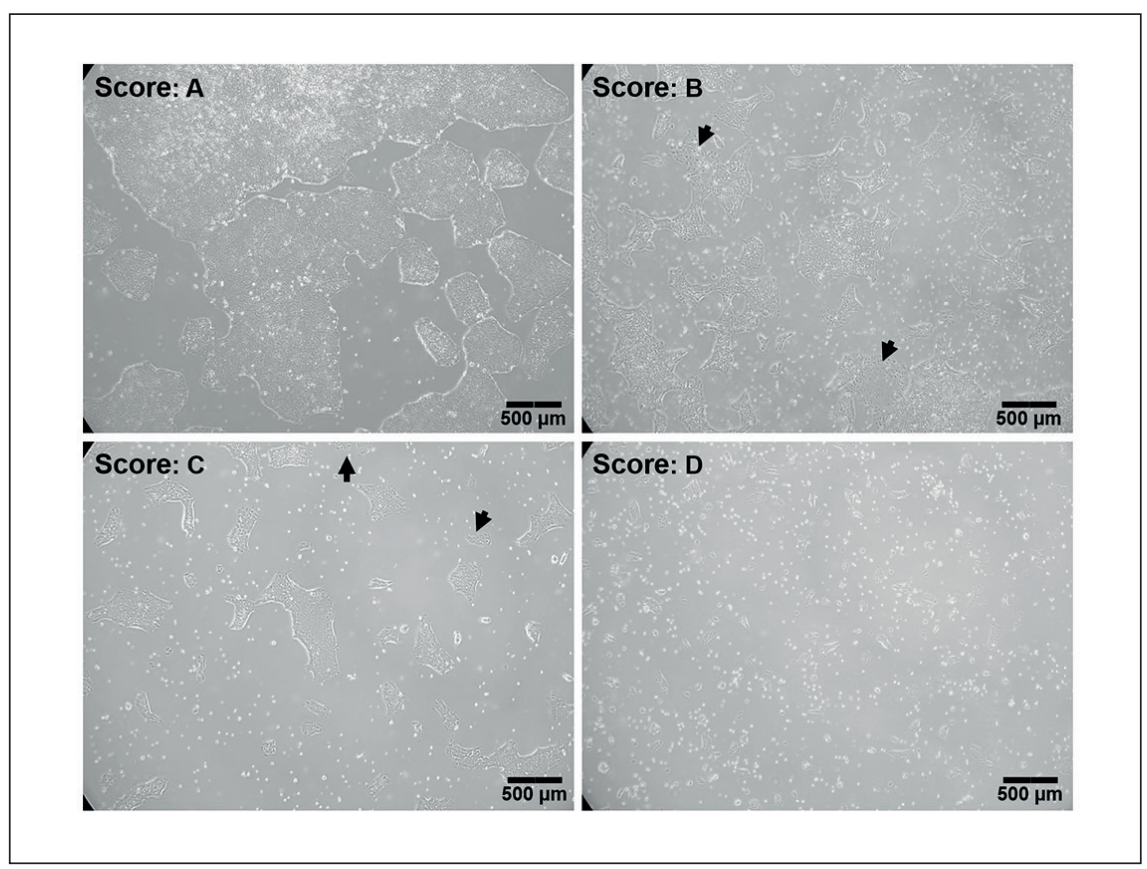

Fig. 2: Representative images of IMR90-C4 scored for daily assessment Score A: Perfect culture (large, dense colonies; low to no differentiation visible) and $>70 \%$ confluent; Score B: Good culture (medium to large colonies; low to medium differentiation visible) and $>50 \%$ confluent; Score C: Fair culture (small to medium colonies; medium to low differentiation visible) and/or $>25 \%$ confluent; Score D: Poor culture (poor adherence, high amount of differentiation, and almost no iPSC visible). Arrowheads indicate areas of differentiation.

into labelled (name of medium, volume, expiration date and date of aliquoting) sterile $50 \mathrm{~mL}$ tubes, and stored at $-20^{\circ} \mathrm{C}$ until use. Aliquots were thawed at $4^{\circ} \mathrm{C}$ overnight when needed.

\subsubsection{Culture and splitting}

Human iPSCs were supplied with $2 \mathrm{~mL} /$ well fresh medium 6 out of 7 days a week. On the $6^{\text {th }}$ day, the cells received double the volume of medium ("double feed") to survive the prolonged period without medium replacement. For routine feeding, the spent medium was aspirated and replaced immediately with fresh fully-supplemented medium equilibrated to RT. Human iPSCs were incubated at $37^{\circ} \mathrm{C}$ and $5 \% \mathrm{CO}_{2}$. Colonies were split when one of the following criteria was reached: (i) colonies reached approx. $>70 \%$ confluency, (ii) colonies were too dense, (iii) cultures showed increasing signs of differentiation, and/or (iv) individual colonies in the well were too large. Stock solution of $0.5 \mathrm{M}$ EDTA (\#15575020; Thermo Fisher Scientific, USA) was diluted $1: 1000$ in PBS $^{(-/)}$and then sterile filtered, aliquoted, and stored at RT (This $0.5 \mathrm{mM}$ EDTA working solution is stable for 6 months at RT.). For the work presented here, only cluster-based passaging was used, and the standard splitting ratio was 1:8-1:12. Spent medium was aspirated, and cultures were washed twice with $1 \mathrm{~mL} /$ well $0.5 \mathrm{mM}$ EDTA by swirling the wells gently and aspirating the EDTA immediately. Then another $1 \mathrm{~mL}$ of EDTA was added and wells were incubated for 4 (cultures on LN521) to 5 (cultures on $\mathrm{MG}$ ) $\min$ at $37^{\circ} \mathrm{C}$ and $5 \% \mathrm{CO}_{2}$. Afterwards, EDTA was aspirated again, and $1 \mathrm{~mL}$ of respective hiPSC medium was added to the well with force, using a $1000 \mu \mathrm{L}$ pipette tip. The medium was triturated exactly twice (again with force: first top of the well, then bottom of the well) to loosen colonies from well surface. The exact volume of the calculated split ratio of the cell suspension was transferred to an already prepared (see 2.1.1.1) new plate and cultured at $37^{\circ} \mathrm{C}$ and $5 \% \mathrm{CO}_{2}$. As a back-up, $1 \mathrm{~mL}$ fresh medium was added to the freshly split well. This back-up well was discarded the next day when split cells passed microscopic assessment. Once a month, the spent medium was transferred to a new well and incubated for an additional week (without cells) in order to detect possible contaminations with bacteria and/or fungi.

\subsubsection{Transition of matrix and medium}

For assay 5 (cell antigen expression + cell count and viability), IMR90-C4 cells were transferred from LN521 and iPS-Brew to MG and mTeSR. Briefly, when cells scored A (for definition see 2.1.1.5) at daily assessment, they were split 1:8 onto MG, but the medium remained $100 \%$ iPS-Brew. The medium was then changed gradually: $75 \%$ iPS-Brew $+25 \%$ mTeSR on day 1 after splitting, $50 \%$ iPS-Brew $+50 \%$ mTeSR on day $2,25 \%$ iPS-Brew $+75 \%$ mTeSR on day 3 until cells were fully transferred to $100 \%$ mTeSR medium on day 4 after splitting.

\subsubsection{Daily assessment and scoring}

hiPSC colonies were microscopically assessed and scored 6 times a week before feeding of the cultures according to the following scoring system (Fig. 2): (A) perfect culture with large, dense colonies, low to no visible differentiation and $>70 \%$ confluency, (B) good culture with medium to large colonies, low to medium visible differentiation and $>50 \%$ confluency, $(\mathrm{C})$ fair culture with small to medium colonies, medium to low visible differentiation and/or $>25 \%$ confluency, (D) poor culture with poor adherence, high differentiation and no visible hiPSC. Only cells that scored A were used for further analysis. Bright field images were taken using an inverted light microscope (CKX41, 
Olympus) equipped with a Color Mosaik 18.2 camera (Visitron Systems) and the SPOT Advanced software (version 4.6.3.8). Every time, overview (40x magnification: Olympus UPlanFLN, $4 \mathrm{x} / 0.3 \mathrm{PhP}$ ) and close-up pictures (200x magnification: Olympus LCAchN, 20x/0.40 PhP) were taken and archived.

\subsubsection{Banking of hiPSCs}

When a cell line is to be used over many experimental cycles or in various projects, a two-tiered cell banking system consisting of a MCB and a WCB (Fig. 1) is state-of-the-art. The MCB is characterized extensively on the day of freezing (assays 1-8). Cells from the MCB are expanded to form the WCBs, which are characterized again (assays 1, 2, 3, 4, 5, and 8) on the day of freezing. Briefly, purchased (IMR90-C4) or generated (Life-Act$e G F P$ ) hiPSC lines were cultured for 5 passages after thawing of the cells. Then hiPSCs were expanded to at least 6-8 full 6-well plates (36-48 individual wells), of which a part was used for quality control assays 1-8 (except for 4 , see 2.5 for details) and the other wells were cryopreserved as described in 2.1.1.1. For different projects and culturing conditions (e.g., single cell culture instead of clusters), different WCBs must be established. One vial of the respective MCB is thawed, cells are cultured for at least 3 passages, and culturing conditions (e.g., matrix/medium) are adjusted as needed (see also 2.1.1.4) before cells are again expanded like for generation of a MCB, and wells are used either for required quality control assays or liquid nitrogen stocks.

\subsubsection{Cryopreservation of hiPSCs}

Cryovials with internal thread (\#710522; Biozym Scientific Gm$\mathrm{bH}$, Hessisch Oldendorf, Germany) were labelled with essential cell line information (MCB/WCB ID, vial number, name of cell line, passage number, date of freezing, initials of researcher) and introduced into a Class II biological safety cabinet. Plates with hiPSCs that were to be cryopreserved were introduced into the same biological safety cabinet, and spent medium was aspirated. It is important to not process more than three wells at a time to avoid prolonged processing time and therefore ensure consistent quality of frozen vials. Culture plates were tilted at a slight angle, and medium was removed by aspirating from the bottom edge of the well, ensuring minimal contact to the surface. Cells were then washed twice by adding $1 \mathrm{~mL} 0.5 \mathrm{mM}$ EDTA (\#15575020; Thermo Fisher Scientific, USA) and gently swirled once before EDTA was aspirated immediately. Then another $1 \mathrm{~mL}$ of $0.5 \mathrm{mM}$ EDTA was added to the respective well, and cells were incubated at $37^{\circ} \mathrm{C}$ and $5 \% \mathrm{CO}_{2}$ for 4 and $5 \mathrm{~min}$ (LN521 and $\mathrm{MG}$, respectively; this incubation time should be adapted to the hiPSC line and matrix used). EDTA solution was aspirated and replaced immediately with $2 \mathrm{~mL}$ CryoStem ${ }^{\mathrm{TM}}$ freezing medium (\#05-710-1E; Biological Industries, USA) and triturated exactly twice to loosen colonies from well surface - first the upper part of the well (1), then the lower part of the well (2). $1 \mathrm{~mL}$ of cell suspension was aliquoted into each labelled cryovial, and cryovials were then placed in an isopropanol freezing container at $-80^{\circ} \mathrm{C}$ overnight. Next day, cells were transferred to a liquid nitrogen tank for long-term storage. Of note, the cryopreservation process described here does not, strictly speaking, yield a homogeneous batch of hiPSCs as not all hiPSCs of all wells were pooled and then equally redistributed before freezing (e.g., as described in Wagner and Welch, 2010; Liu and Chen, 2014; Shibamiya et al., 2020). However, in our opinion such a procedure is not feasible for all research laboratories, as often the infrastructure for such a large-scale freezing process is not available.

\subsubsection{Thawing of hiPSC clusters}

Before starting the thawing procedure, appropriate amounts of matrix-coated wells (2 6-wells per line) were prepared (see 2.1.1.1). Plates were allowed to equilibrate at RT for at least 30 min prior to starting of the thawing process.

A $15 \mathrm{~mL}$ conical tube was introduced into a Class II biological safety cabinet and labelled according to the hiPSC line to be thawed. $4 \mathrm{~mL}$ of ice-cold and $4 \mathrm{~mL}$ of hiPSC medium equilibrated to RT were also placed into the Class II biological safety cabinet. Cells to be thawed were removed from the liquid nitrogen tank and devolatilized in the Class II biological safety cabinet before they were thawed quickly at $37^{\circ} \mathrm{C}$ using a water bath until only a small clump of ice (pea size) was still visible. Using a $1000 \mu \mathrm{L}$ pipette tip, the cell solution was carefully transferred to the prepared $15 \mathrm{~mL}$ conical tube. $1 \mathrm{~mL}$ of fresh, cold hiPSC medium was added dropwise to the cell suspension, followed by $2 \mathrm{~mL}$ cold medium. The vial was shaken gently to allow gradual equilibration of the cells to the changing microenvironment after every few drops and each respective additional mL. Another $1 \mathrm{~mL}$ of cold hiPSC medium was added to the cryopreservation vial for washing and then also transferred dropwise to the $15 \mathrm{~mL}$ tube. Cells were centrifuged at $200 \mathrm{x}$ g at RT for $5 \mathrm{~min}$. The supernatant was carefully aspirated, $4 \mathrm{~mL}$ of hiPSC medium at RT were added, and the cell pellet was carefully dislodged using a $5 \mathrm{~mL}$ serological pipette by pipetting up and down not more than twice. The supernatant was removed from prepared matrix-coated wells, and they were washed if appropriate (see 2.1.1.1). $2 \mathrm{~mL}$ per well cell suspension was added to each prepared matrix-coated well, and the 6-well plate was moved in a shape of 8 three times to evenly distribute cells over the whole surface of the well. Human iPSCs were incubated at $37^{\circ} \mathrm{C}$ and $5 \% \mathrm{CO}_{2}$, and medium was changed the next day.

\subsection{Assay \# 1: Microscopic assessment of colony/ cell morphology}

Microscopic assessment of the cells was performed as described in 2.1.2.5. Colonies should represent score A (see also 2.1.1.5) and appear compact, flat, have well-defined, smooth edges, and not show signs of premature differentiation (e.g., cracks between the cells that appear almost white). Cells should be round, small, and have a high nucleus-to-cytoplasm ratio and prominent nucleoli (Wakui, 2017).

\subsection{Assay \#2: Mycoplasma PCR}

Mycoplasma PCR was performed using the PCR Mycoplasma Test Kit I/C (PK-CA91-1024, PromoCell, Heidelberg, Germany) according to the manufacturer's instructions. The kit includes a 
positive (DNA-fragment of the $M$. orale genome) and a negative control and detects: A. laidlawii, $M$. agalactiae, $M$. arginini, $M$. arthritidis, M. bovis, M. cloacale, M. falconis, M. faucium, $M$. fermentans, M. hominis, M. hyorhinis, M. hyosynoviae, M. opalescens, $M$. orale, $M$. primatum, $M$. pulmonis, $M$. salivarium, $M$. spermatophilum, and M. timone. It is not suitable for detection of M. pneumoniae, Ureaplasma urealyticum, or other clinically associated species that are not typically found as cell culture contaminants.

\subsection{Assay \#3: Short tandem repeat (STR) genotyping}

At the time of banking, genomic DNA of one 6-well of hiPSC was extracted using the peqGOLD Tissue DNA Mini Kit (VWR International $\mathrm{GmbH}$, Darmstadt) following the manufacturer's instructions.

For STR-analysis (carried out at the Institute of Forensic Medicine, University Clinic Duesseldorf), a single-source template DNA (0.5 ng) was amplified using the PowerPlex ${ }^{\circledR} 21$ System (Promega, USA). Amplification products were mixed with WEN Internal Lane Standard 500 and analyzed with an ABI 3130 Genetic Analyzer (Applied Biosystems ${ }^{\circledR}$, USA). Results were analyzed using GeneMapper ${ }^{\circledR}$ ID software, version 3.2. The following genetic loci were analyzed: Amelogenin, D3S1358, D1S1656, D6S1043, D13S317, Penta E, D16S539, D18S51, D2S1338, CSF1PO, Penta D, TH01, vWA, D21S11, D7S820, D5S818, TPOX, D8S1179, D12S391, D19S433, and FGA.

As it is theoretically possible to identify donors on the basis of published STR profiles (Pamies et al., 2017), we decided against showing the results of all 21 analyzed STR loci (although all analyzed loci matched between IMR90-C4 and Life-Act-eGFP hiPSC lines). Instead, we focus on the 14 already published loci: D3S1358, D13S317, D16S539, D18S51, CSF1PO, TH01, vWA, D21S11, D5S818, D7S820, TPOX, D8S1179, FGA, AMEL (Cellosaurus CVCL_0347¹).

\subsection{Assay \#4: Cytogenetic analysis by classical G-banding}

Cytogenetic analyses were performed using GTG-banding of chromosomes adapted from Howe et al. (2014). In detail, when cells were expanded for banking, one matrix-coated T25 flask with respective hiPSCs was prepared in parallel to ensure that the cytogenetic analysis took place in the same passage the cells were banked in. Cells were transferred to the Institute of $\mathrm{Hu}-$ man Genetics (University Clinic Duesseldorf) and analyzed after a resting period of $24 \mathrm{~h}$ (Note that cells must be in proliferative phase, therefore cultures should not exceed a confluency of $50 \%$ at time of transport). Culture medium was replaced the next day (cells should have reached $\sim 80 \%$ confluency). To arrest cells in metaphase, $10 \mu \mathrm{L} / \mathrm{mL}$ colcemid (a spindle poison) was added to the cultures and incubated for 2-5 h. An inverted microscope was used to check for rounded cells. Cell supernatant was transferred to a $15 \mathrm{~mL}$ conical tube, which was set aside for later use. Cells were gently washed with $2 \mathrm{~mL}$ Hanks' solution. $1 \mathrm{~mL}$ prewarmed $\left(37^{\circ} \mathrm{C}\right)$ trypsin was added to the cells and incubated for 2-5 min. The cells were tapped vigorously to dislodge cells and again checked under an inverted microscope. This cell suspension was then transferred back to the $15 \mathrm{~mL}$ conical tube with medium and centrifuged at $1000 \mathrm{x} g$ for $10 \mathrm{~min}$. Supernatant was discarded, and the cell pellet was resuspended using $10 \mathrm{~mL}$ $0.075 \mathrm{M}$ prewarmed $\mathrm{KCl}\left(37^{\circ} \mathrm{C}\right)$ on a vortexer set to medium speed (the hypotonic $\mathrm{KCl}$ solution causes cell swelling). Cells were incubated in $\mathrm{KCl}$ for $20 \mathrm{~min}$ at RT, followed by centrifugation at $1000 \mathrm{x} g$ for $10 \mathrm{~min}$. The supernatant was removed, and the cell pellet was resuspended in $8 \mathrm{~mL}$ of fresh Carnoy's fixative (methanol/glacial acetic acid at a ratio of 3:1) on a vortexer (see above). Cells were centrifuged at $1000 \mathrm{x}$ g for $10 \mathrm{~min}$ and supernatant was removed. The cell pellet was resuspended in Carnoy's fixative (can be stored at $4^{\circ} \mathrm{C}$ for up to one year). For preparation of slides, cells were centrifuged at $1000 \mathrm{x}$ g for $10 \mathrm{~min}$, and most of the supernatant was discarded, leaving only $\sim 0.5 \mathrm{~mL}$ to gently resuspend the cells. Three drops of the cell suspension were dropped on a tilted slide $\left(\sim 45^{\circ}\right)$ from a distance of 5-10 $\mathrm{cm}$, and the suspension was left to run over the slide to ensure that chromosomes were properly separated. One large drop of fresh Carnoy's fixative was added to the slide before it was left to dry for at least $10 \mathrm{~min}$ (slide should be completely dry). In the meantime, the following solutions were prepared in separate Coplin jars: (i) $80 \mathrm{~mL}$ buffer solution (di-sodium hydrogen phosphate/potassium dihydrogen phosphate) $+1 \mathrm{~mL} 10 \mathrm{x}$ trypsin $(0.5 \%)$, and (ii) $100 \mathrm{~mL} \mathrm{NaCl}(0.9 \%)$. Each slide was dipped in jar (i) for $3 \mathrm{~min}$ and then rinsed shortly in jar (ii). Afterwards slides were allowed to dry. Fresh Giemsa staining solution (Gurr Buffer and Giemsa Stain in a ratio of $3: 1$ ) was prepared and used to cover the entire slide for $5 \mathrm{~min}$. Then slides were washed with distilled water and dried at RT. Slides were covered using Entellan ${ }^{\circledR}$ (\#107961, Merck, Darmstadt, Germany; avoiding air bubbles under the cover slip). This treatment allows to discriminate between the relatively gene-poor heterochromatic regions (AT-rich), which stain darkly, and more transcriptionally active euchromatic regions (GC-rich). Subsequently, 2-16 slides were scanned using the slide scanning system Metafer from MetaSystems (MetaSystems Hard \& Software GmbH, Altlussheim, Germany). The cytogenetic analysis was done with the karyotyping system Ikaros from MetaSystems. Up to 24 metaphases were analyzed and karyotyped. The karyotype was described according to (ISCN, 2016), where a clonal aberration is defined as at least two cells with the same aberration if the aberration is a chromosome gain or structural rearrangement, or at least three cells if the abnormality is a loss of a chromosome. The quality of the karyotypes ranged from 200-350 band levels.

\subsection{Assay \#5: Cell antigen expression (\#5.1) and cell count and viability (\#5.2)}

Human iPSC cultures were analyzed at the time of banking ( 3 to 5 days after the last split at no more than $80 \%$ confluency). We used the BD ${ }^{\mathrm{TM}}$ Human Pluripotent Stem Cell Transcription Factor Analysis FACS Kit (RUO \#560589; Becton, Dickinson and Company (BD), USA) including PE mouse anti-human Nanog,

$\overline{1}$ Cellosaurus CVCL_0347 Web page Cellosaurus cell line IMR-90 (CVCL_0347). https://web.expasy.org/cellosaurus/CVCL_0347 (accessed 18.01.2021) 
Tab. 1: Flow cytometry setup

\begin{tabular}{|l|l|l|l|l|l|}
\hline Fluorochrome & FITC & PE & PerCP & Alexa657 & Fvs 510 \\
\hline Laser lines & $488 \mathrm{~nm}$ & $488 \mathrm{~nm}$ & $488 \mathrm{~nm}$ & $633 \mathrm{~nm}$ & $405 \mathrm{~nm}$ \\
\hline Emission filter & $530 / 30$ & $585 / 42$ & $670 \mathrm{LP}$ & $660 / 20$ & $510 / 50$ \\
\hline
\end{tabular}

PerCP-Cy ${ }^{\mathrm{TM}} 5.5$ mouse anti-OCT3/4, Alexa Fluor ${ }^{\circledR} 647$ mouse anti-Sox2, as well as the respective isotype controls PE mouse IgG1, $\kappa$ isotype control, PerCP-Cy5.5 mouse IgG1, $\kappa$ isotype control, and Alexa Fluor ${ }^{\circledR} 647$ mouse IgG2a, $\kappa$ isotype control. According to the manufacturer's manual, we combined this kit with an additional antibody against the membrane-bound glycolipid SSEA4 (\#560126; BD, USA) and the respective isotype control (\#555578; BD, USA). To be able to assess cell viability at the same time, we also included a live staining of the cells using fixable viability stain (Fvs) 510 (\#564406; BD, USA).

Briefly, cells were microscopically assessed as described under 2.2 and used when scored A. Then 8-12 wells were singularized using TrypLE ${ }^{\mathrm{TM}}$ Select Enzyme (\#12563-011; Thermo Fisher Scientific, USA). Approx. 1 x $10^{6}$ cells per staining condition (unstained, Fvs 510 only, isotypes + Fvs 510, all stained (NanogPE, OCT3/4-PerCP, Sox2-Alexa657, SSEA4-FITC + Fvs 510), the fluorescence minus one (FMO) control for SSEA-4 (NanogPE, OCT3/4-PerCP, Sox2-Alexa647 + Fvs 510)) and single stained controls for each fluorochrome were collected in respective Eppendorf tubes. Cells were stained with Fvs 510 for 15 min at RT. Then cells were washed using staining buffer $\left(\mathrm{PBS}^{(-/)}+2 \%\right.$ heat-inactivated KnockOut ${ }^{\mathrm{TM}}$ Serum Replacement (\#10828010; Thermo Fisher Scientific, USA)). After washing, cells were stained for SSEA4-FITC and respective isotype control for 25 min at RT. Then cells were again washed and fixed in BD Cytofix fixation buffer (provided) for $20 \mathrm{~min}$ at RT. Afterwards they were washed again and stored in $\mathrm{PBS}^{(-/)}$at $4{ }^{\circ} \mathrm{C}$ overnight. The next day, cells were permeabilized using BD Perm/Wash buffer (provided) for $20 \mathrm{~min}$ at RT before staining for Nanog-PE, OCT3/4-PerCP, Sox2-Alexa647 and respective isotype controls for $30 \mathrm{~min}$ at RT. Cells were washed in PermWash Buffer, resuspended in staining buffer, and analyzed using a BD FACSCanto $^{\text {TM }}$ II system (see Tab. 1 for setup) using BD FACS Diva Software Version 6.1.3. At least 20,000 events per condition were recorded from the scatter gate, the applied gating strategy is included in the respective Figures 3 and S12. Further analysis was performed using Flow Jo V10.7.1.

\subsection{Assay \#6: Cell gene expression (PluriTest ${ }^{\mathrm{TM}}$ )}

One 6-well of hiPSC at the time of banking was washed twice with $1 \mathrm{~mL} 0.5 \mathrm{mM}$ EDTA. Cells were incubated with $1 \mathrm{~mL}$ EDTA for $5 \mathrm{~min}\left(37^{\circ} \mathrm{C}, 5 \% \mathrm{CO}_{2}\right)$. EDTA was then aspired and discarded. Cells were resuspended in $1 \mathrm{~mL}$ medium and collected in a $1.5 \mathrm{~mL}$ Eppendorf tube. Samples were centrifuged for $3 \mathrm{~min}$ at $500 \mathrm{x}$ g. Supernatant was aspirated, and cell pellets were stored at $-80^{\circ} \mathrm{C}$ until they were shipped to Thermo Fisher Scientific
(USA) on dry ice where the PluriTest ${ }^{\mathrm{TM}}$ assay (\#A38154) was performed.

The PluriTest ${ }^{\mathrm{TM}}$ assay compares the transcriptional profile of a sample to a reference set of $>450$ cells and tissue types (incl. 223 hESCs, 41 iPSCs, somatic cells, and tissues). The pluripotency score (PS) indicates how strongly a model-based pluripotency signature is expressed in the analyzed samples. A PS over 20 indicates that the sample is more like the pluripotent samples of the reference set than the other samples. The novelty score (NS) indicates the general model fit for a given sample. A NS below 1.67 indicates that the tested samples can be well reconstructed based on existing data from other well-characterized iPSC and ESC lines (Müller et al., 2011; Müller, 2014).

\subsection{Assay \#7: Embryoid body (EB) formation}

The EB formation protocol was adapted from Kurosawa (2007). In detail, for each hiPSC line, two wells of a 6-well plate were used for EB-formation at time of banking (Day 0). This yields enough material for both plating onto gelatine for subsequent immunocytochemical analysis (see 2.8.1) and pellet generation for Scorecard ${ }^{\mathrm{TM}}$ analysis (see 2.8.2). EB medium $(50 \mathrm{~mL}$ : 39 mL DMEM, high glucose, GlutaMAX ${ }^{\mathrm{TM}}$ (\#31966-021; gibco by life technologies ${ }^{\mathrm{TM}}$, USA), $10 \mathrm{~mL}$ KnockOut ${ }^{\mathrm{TM}}$ Serum Replacement (\#10828010; Thermo Fisher Scientific, USA), $0.5 \mathrm{~mL}$ non-essential amino acids (\#11140-050; gibco by life technologies $^{\mathrm{TM}}$, USA), $0.5 \mathrm{~mL}$ penicillin/streptomycin (\#P0607100; PAN Biotech, Aidenbach, Germany), $91 \mu \mathrm{L} 2$-mercaptoethanol (\#31350-010; gibco by life technologies ${ }^{\mathrm{TM}}$, USA)) was equilibrated in a T75 flask with $\mathrm{CO}_{2}$ permeable lid at $37^{\circ} \mathrm{C}$ and $5 \% \mathrm{CO}_{2}$ for $30 \mathrm{~min} .10 \mathrm{~cm}$ ultralow adherence plates (Nunc ${ }^{\mathrm{TM}}$ HydroCell; \#174911; Thermo Fisher Scientific, USA; 2 per line - note that these plates are no longer available. Thermo Fisher Scientific suggests Nunclon ${ }^{\mathrm{TM}}$ Sphera $^{\mathrm{TM}}$ dishes \#174945 as an alternative) were filled with $19 \mathrm{~mL}$ EB medium plus $10 \mu \mathrm{M}$ Rock inhibitor (\#HB2297; hellobio, UK). Medium of respective hiPSCs was aspirated and discarded. Cells were washed once with $\mathrm{PBS}^{(+/+)}$, and $1 \mathrm{~mL}$ EB medium + Rock inhibitor per well was added. StemPro ${ }^{\circledR}$ EZPassage ${ }^{\text {TM }}$ passaging tool (\#23181-010; Invitrogen by Thermo Fisher Scientific, USA) was used once vertically, once horizontally on each well to assure hiPSC pieces of equal size. A cell scraper (\#83.1832; Sarstedt AG \& Co. KG, Nümbrecht, Germany) was used to harvest the hiPSC pieces, and the clusters of one well of the 6-well plate were transferred to one ultralow adherence plate containing $19 \mathrm{~mL}$ EB medium. Cell clusters were incubated at $37^{\circ} \mathrm{C}$ and $5 \% \mathrm{CO}_{2}$. On days 2,4 and 6 , spent medium was replaced by fresh $\mathrm{EB}$ induction medium

2 doi:10.14573/altex.2101221s 
$(20 \mathrm{~mL})$ by transferring the entire volume of each plate into a separate $50 \mathrm{~mL}$ conical falcon tube. EBs were allowed to settle at the bottom of the tube for $10 \mathrm{~min}$ at RT. Then the supernatant was cautiously removed using a $25 \mathrm{~mL}$ serological pipette, and $20 \mathrm{~mL}$ fresh EB medium was added to each tube. Cells were transferred back into the old culturing plates by pouring to avoid unnecessary sheer stress. Proliferating EBs grew in size over the culture time of 7 days.

\subsubsection{Assay \#7.1: Immunocytochemistry of markers of all three germ layers}

\subsubsection{Spontaneous differentiation of EBS}

On day 7, three 24-well plates (black plates with imaging bottom would be preferable, here normal cell culture plates were used) were coated with $250 \mu \mathrm{L} 0.2 \%$ gelatin (diluted from $2 \%$ gelatin (\#G1393-20ML; Sigma Aldrich, USA) using $\mathrm{PBS}^{(+/+)}$; gelatin should be prewarmed to $37^{\circ} \mathrm{C}$ in a heating cabinet before use) for $20 \mathrm{~min}$ at RT (open lid). Then gelatin solution was aspirated completely, and $750 \mu \mathrm{L}$ EB medium per well were added. One EB of approx. $300 \mu \mathrm{m}$ in size per well was gently plated using a 1000 $\mu \mathrm{L}$ pipette and allowed to settle for $5 \mathrm{~min}$. EBs were incubated at $37^{\circ} \mathrm{C}$ and $5 \% \mathrm{CO}_{2}$, and half of the spent medium was replaced every other day while carefully avoiding EB wash-off.

On days 11, 14 and 21, differentiated EBs were fixed by adding 12\% PFA (\#P6148-1KG; Merck KGaA, Darmstadt, Germany), resulting in a final PFA concentration of $4 \%$, and incubated for $15 \mathrm{~min}$ at RT. Then, EBs were washed twice using $1 \mathrm{~mL} \mathrm{PBS} \mathrm{PS}^{(-/)}$ per well, sealed with parafilm, and stored at $4^{\circ} \mathrm{C}$ until staining (Note that even if EBs are washed off at some point during the differentiation phase, it is worthwhile to check for differentiated cells under a microscope before discarding the sample).

\subsubsection{Immunocytochemical staining of differentiated EBS}

Before staining, all wells were analyzed under a light microscope to judge from the morphological structures of the differentiated cells which antibody staining (which germ layer marker) would be most promising as each well is stained with one marker. Afterwards 24-well plates were equilibrated at RT for $15 \mathrm{~min}$. Then PBS was carefully removed, and $200 \mu \mathrm{L} /$ well permeabilization buffer $(0.05 \%$ PBS-Tween 20$)$ was added and incubated at RT for 5 min. Wells were washed twice with $0.5 \mathrm{~mL} \mathrm{PBS}^{(++)}$for $5 \mathrm{~min}$, followed by addition of $200 \mu \mathrm{L} /$ well blocking solution $(1 \%$ BSA in $\left.\mathrm{PBS}^{(+/+)}\right)$and incubation at RT for $30 \mathrm{~min}$. Primary antibody $(\mathrm{AB})$ solutions were prepared in primary $\mathrm{AB}$ dilution buffer (10 mL: $1 \mathrm{~mL} \mathrm{10 \%} \mathrm{BSA,} 7.5 \mu \mathrm{L}$ Tween20, fill up to $10 \mathrm{~mL}$ with PBS $^{(+/+)}$): (i) 1:100 monoclonal anti- $\beta$-tubulin III (TUBB3) antibody produced in mouse, clone SDL.3D10 (\#T8660; Sigma A1drich, USA), (ii) 1:200 monoclonal anti-actin, smooth muscle actin (SMA) produced in mouse, clone 1A4 (\#M0851; Agilent Dako, USA), and (iii) 1:200 monoclonal anti- $\alpha$-feto protein (AFP) antibody produced in mouse, clone 1G7 (\#WH0000174M1; Sigma Aldrich, USA). Blocking solution was discarded and $200 \mu \mathrm{L}$ per well of the respective primary $\mathrm{AB}$ solution was added. Plates were incubated over night at $4^{\circ} \mathrm{C}$ on a rocking plate. Next day, primary AB solution was discarded, and cells were washed twice with $0.5 \mathrm{~mL} \mathrm{PBS}^{(+/)}$for $5 \mathrm{~min}$. Secondary ABs (For IMR90-C4 SMA and for all Life-Act-eGFP stainings 1:100 polyclonal goat anti-mouse $\mathrm{IgG}(\mathrm{H}+\mathrm{L})$ highly cross-adsorbed secondary antibody, Alexa Fluor 546 was used (\#A11030; Thermo Fisher Scientific, USA), for Life-Act-eGFP TUBB3 and AFP 1:200 polyclonal goat anti-mouse $\operatorname{IgG}(\mathrm{H}+\mathrm{L})$ cross-adsorbed secondary antibody, Alex Fluor 488 was used (\#A11001; Thermo Fisher Scientific, USA).) were prepared in secondary AB dilution buffer $(0.05 \%$ PBS-Tween 20$) .200 \mu \mathrm{L} /$ well of secondary AB solution were added, and wells were incubated at $37^{\circ} \mathrm{C}$ in the dark for $30 \mathrm{~min}$. Wells were washed twice with $0.5 \mathrm{~mL}$ per well $\mathrm{PBS}^{(+/)}$ at RT for $5 \mathrm{~min}$ and covered with $200 \mu \mathrm{L} \mathrm{PBS}^{(+/+}$for visualization using a fluorescent microscope. Pictures of differentiated EBs from IMR90-C4 were taken with an Olympus BX60 fluorescent microscope combined with an Olympus ColorView XS digital camera and Soft Imaging Systems analysis software. Images of Life-Act-eGFP EBs were taken at RT using a laser scanning microscope (LSM710, Zeiss) with an EC Plan-Neofluar 10x/ $0.30 \mathrm{M} 27$ objective lens and a photo-multiplier-tube point detector. Acquisition software was ZEN Black (Zeiss).

\subsubsection{Assay \#7.2: Scorecard ${ }^{\mathrm{TM}}$ assay}

At least fifteen 7-day-old proliferating EBs that were $300 \mu \mathrm{m}$ in size were collected in a $50 \mathrm{~mL}$ tube and centrifuged at $500 \mathrm{x}$ g for $3 \mathrm{~min}$. The supernatant was discarded, and the pellet was resuspended in $1 \mathrm{~mL} \mathrm{PBS}^{(+/)}$and transferred to a $1.5 \mathrm{~mL}$ tube. EBs were again centrifuged at $500 \mathrm{x}$ g for $3 \mathrm{~min}$, and the supernatant was discarded. Dry pellets were stored at $-80^{\circ} \mathrm{C}$. As a control, a cell pellet of the respective undifferentiated hiPSC-line was generated as described under 2.7. The pellets were then shipped to Thermo Fisher Scientific (USA) on dry ice where the Scorecard $^{\mathrm{TM}}$ assay (\#A16179) was performed.

The Scorecard ${ }^{\mathrm{TM}}$ assay (Bock et al., 2011) uses a proprietary algorithm to predict trilineage differentiation potential based on a panel of 94 genes relative to a reference set of nine undifferentiated pluripotent stem cell lines.

\subsection{Assay \#8: Trypan blue exclusion, microscopic assessment}

Human iPSCs were thawed as described under 2.1.1.2. Cell density and colony/cell morphology were assessed microscopically on day 1 after thawing and when the cells reached a confluency of approx. $80 \%$ and needed splitting (day 3 for IMR90-C4 and day 2 for Life-Act-eGFP). For the trypan blue exclusion assay, medium of one well per line was aspirated, and cells were washed twice with $1 \mathrm{~mL} \mathrm{PBS}^{(-/)}$. $1 \mathrm{~mL} /$ well TrypLETM Select Enzyme (\#12563-011; Thermo Fisher Scientific, USA) was added, and cells were incubated at $37^{\circ} \mathrm{C}$ and $5 \% \mathrm{CO}_{2}$ for $5 \mathrm{~min}$. The enzymatic reaction was stopped using $3 \mathrm{~mL} /$ well KnockOut ${ }^{\mathrm{TM}}$ DMEM medium with 10\% KnockOut ${ }^{\mathrm{TM}}$ Serum Replacement (\#10828010; Thermo Fisher Scientific, USA). Cells were pipetted up and down 5 times to ensure a single cell solution. $50 \mu \mathrm{L}$ of this cell suspension was placed in a $1.5 \mathrm{~mL}$ tube, and $50 \mu \mathrm{L} 0.4 \%$ trypan blue solution (\#T8154; Sigma Aldrich, USA) was added and mixed by pipetting up and down until an even distribution 


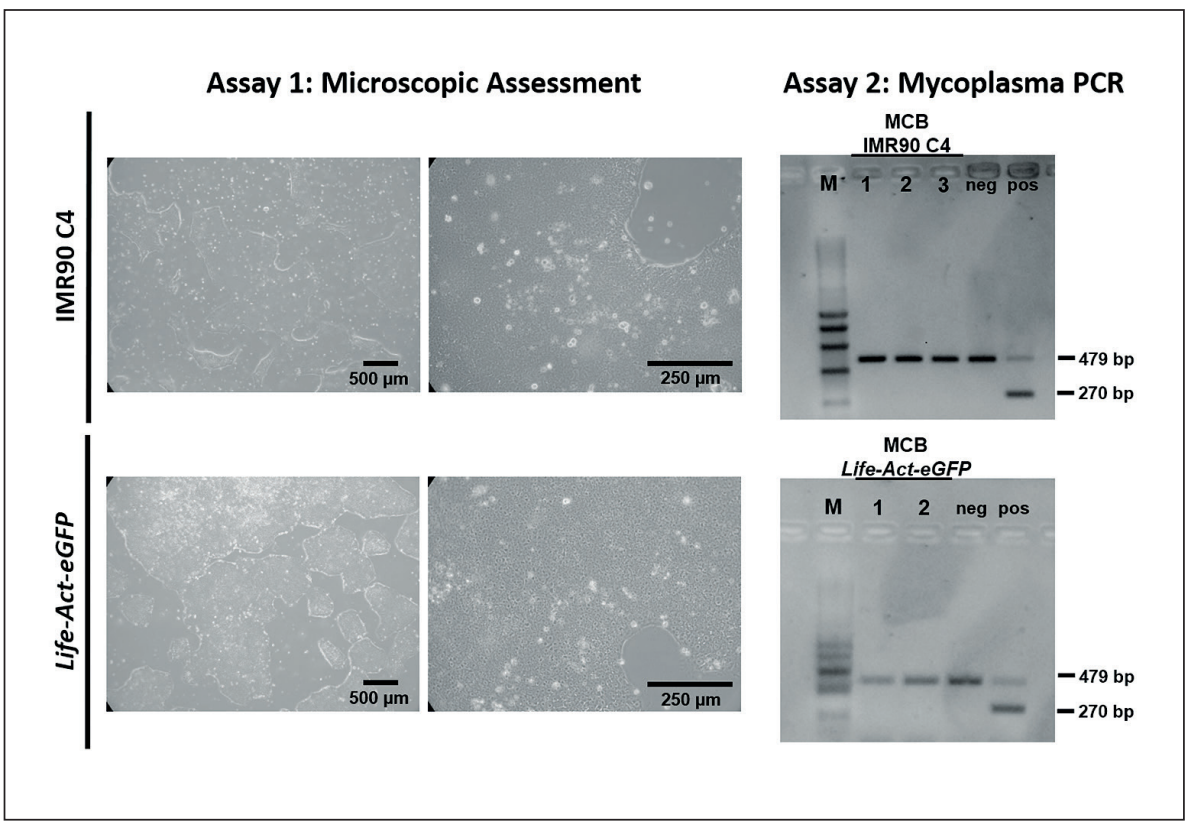

Fig. 3: Results of microscopic assessment of colony/cell morphology (assay 1; left) and mycoplasma PCR (assay 2; right) for MCBs IMR90-C4 (upper panel) and Life-Act-eGFP (lower panel) Left: Representative microscopic images. Right: Results of mycoplasma PCR. M, marker; neg, negative (internal DNA) control (479 bp); pos, positive control (270 bp); bp, base pairs of the color was reached. Cells were incubated for 2-3 min at RT, and $10 \mu \mathrm{L}$ of the stained cells was transferred to a C-Chip disposable hemocytometer (\#DHC-N01; NanoEnTek, Korea). Pictures were taken within the first 5 min after the dye was added, as the dye itself will lead to cytotoxicity when incubated for too long. The percentage of viable cells was calculated using the following equation:

$\%$ viable cells $=[1.00-($ number of blue cells/number of total cells $)] \times 100$

\section{Results and discussion}

\subsection{Assessment of colony/cell morphology (assay 1) and exclusion of mycoplasma contamination (assay 2)} It is well known that hiPSC cultures are prone to spontaneous differentiation, especially during longer culturing periods (Pamies et al., 2017). Therefore, we established a daily assessment of colony and cell morphology using a scoring system from (A) perfect culture with large, dense colonies, low to no visible differentiation, and $>70 \%$ confluency to (D) poor culture with poor adherence, high amount of differentiation, and no visible hiPSC (for details see 2.1.2.5). We assessed the colony and cell morphology according to criteria defined previously (Pamies et al., 2017; Wakui, 2017). In recent years, there have been efforts to automate the quality ranking of hiPSC cultures by using time-lapse microscopy and automated image analysis assessing (i) hiPSC doubling time, (ii) compactness of colonies, (iii) smoothness of colony borders, (iv) sensitivity of colonies to change of medium, (v) degree of dead cells, and (vi) prevalence of spontaneously differentiated cells (Maddah et al., 2014). This non-invasive system to assess hiPSC colony and cell morphology might be useful for high-throughput hiPSC laboratories, but for a normal academic lab we conclude that manually conducted daily microscopic assessment as described here is probably more feasible and, combined with the other assays described in this paper, sufficient to ensure quality of the cultures. Our two MCB cultures revealed a stem cell-like phenotype with compact, flat colonies consisting of small, round cells with a high nucleus-to-cytoplasm ratio, prominent nucleoli, and a general lack of spontaneously differentiated cells (Fig. 3, left panel).

It is estimated that up to $35 \%$ of cell cultures currently in use are contaminated by mycoplasma (Hay et al., 1989; Chi, 2013; Pamies et al., 2017), which can result in major changes of the cellular phenotype, e.g., increased sensitivity to apoptosis (Hay et al., 1989), changes in cellular morphology, growth and viability (Rottem and Barile, 1993; Langdon, 2004), occurrence of chromosomal aberrations (Drexler and Uphoff, 2002), altered cellular metabolism (Armstrong et al., 2010), changes in cell membrane antigenicity (Timenetsky et al., 2006), reduced transfection efficiency (Chi, 2013), and alterations of cytokine expression (Chi, 2013). Therefore, it is consensus that cultures should be screened for mycoplasma contamination at time of cell arrival and additionally every three months (Pamies et al., 2017). Our approach is in line with these standards, using a quarantine incubator in another laboratory and performing mycoplasma PCR analysis before the cells are transferred to the actual stem cell laboratory. Furthermore, we perform additional mycoplasma PCRs once a month, and cultures are discarded immediately upon a positive test result. Although no standardized PCR-based method exists to date (Pamies et al., 2017), we chose a commercial PCR-based kit for the detection of possible mycoplasma contamination in our cell cultures, as this is faster and more convenient than other assays including broth/agar culture, assays for mycoplasma-characteristic enzyme activities, and DNA staining (Pamies et al., 2017), which take from several 
days to weeks and are therefore not practical in an academic research setting. The kit we chose is able to detect 19 (for details see 2.3) different mycoplasma types, including the ones that account for the vast majority of contaminations in cell culture, i.e., $M$. hyorhinis, M. arginine, M. fermentans, A. laidlawii, M. hominis, M. orale, M. bovis and M. pulmonis (Bruchmüller et al., 2006; ISCBI, 2009; Nikfarjam and Farzaneh, 2012). This test confirmed that the analyzed MCB samples of IMR90-C4 and Life-Act-eGFP were mycoplasma free (Fig. 3, right panel).

\subsection{Identity assessment by short tandem repeat (STR) genotyping (assay 3 )}

One of the most important principles of Good Cell Culture Practice is cell line authentication (Coecke et al., 2005; Yaffe et al., 2016). Up to $40 \%$ of all analyzed cell lines have been falsely identified (Nelson-Rees et al., 1981; MacLeod et al., 1999; Stacey et al., 2000; Buehring et al., 2004; Hughes et al., 2007; Rojas et al., 2008; Dirks et al., 2010; Yu et al., 2015). Therefore, leading cell banks (ATCC, CellBank Australia, DSMZ, ECACC, JCRB, and RIKEN) introduced the technique of STR profiling to address this issue (Pamies et al., 2017). According to the International Cell Line Authentication Committee (ICLAC), the analysis of at least eight STR loci is required for cell line authentication (Sarafian et al., 2018), while ISCBI recommends the use of the core 13 loci commonly used in forensic medicine (Xu et al., 2013). Commercially available kits on the market typically use a common subset of 16 different STR loci, which ensures comparison between different providers (Andrews et al., 2015). Another approach is the analysis of single-nucleotide polymorphisms (SNPs), however they are discussed to be too detailed and expensive to be used for cell line authentication on a regular basis (Ntai et al., 2017). Comparing these two methods, individual STRs are more polymorphic (Freedman et al., 2015; Sarafian et al., 2018) and are widely applied in forensic analysis (Almeida et al., 2016), but spontaneous mutations or epigenetic changes due to long term culture (Lorsch et al., 2014) and the possible cross-contamination with cell lines from other species (e.g., mice) will not be detected (Freedman et al., 2015). 52-plex SNP assays seem to have the same rate of discrimination as 16-plex STR assays, but a centralized, online reference database for SNP assays is lacking (Freedman et al., 2015; Pamies et al., 2017).

Therefore, we decided to use STR analysis for cell line authentication in cooperation with the Institute for Forensic Medicine at the University Clinic Duesseldorf. STR-analysis of gDNA isolated from both MCBs at the time of banking affirmed that IMR90-C4 are homozygous for two of the analyzed STR loci shown here (D18S51 and AMEL) and heterozygous for the other 12 (Tab. 2; middle column), which exactly matches the results for Life-Act-eGFP (Tab. 2; right column). This was expected, as IMR90-C4 is the parental line of Life-Act-eGFP. Both STR profiles also match alleles of the initial IMR90-C4 parent line IMR90 lung fibroblasts (Tab. 2; left column) in the 14 STR loci that are publicly available on Cellosaurus (Bairoch, 2018). Performing STR-analysis not only for MCBs but also for WCB
Tab. 2: Results of short tandem repeat (STR) genotyping (assay 3)

A single-source template DNA (0.5 ng) was amplified using the PowerPlex ${ }^{\circledR} 21$ system (Promega). Amplification products were mixed with WEN Internal Lane Standard 500 and analyzed with an ABI 3130 Genetic Analyzer (Applied Biosystems ${ }^{\circledR}$ ). Results were analyzed using GeneMapper ${ }^{\circledR}$ ID software, version 3.2. Only the previously published 14 loci of IMR90 lung fibroblasts are listed, see Section 2.4 for details.

\begin{tabular}{|l|l|l|l|}
\hline STR locus & $\begin{array}{l}\text { IMR90 lung } \\
\text { fibroblasts }\end{array}$ & $\begin{array}{l}\text { MCB IMR90- } \\
\text { C4 }\end{array}$ & $\begin{array}{l}\text { MCB } \\
\text { Life-Act- eGFP }\end{array}$ \\
\hline D3S1358 & 14,15 & $\mathbf{1 4 , 1 5}$ & $\mathbf{1 4 , 1 5}$ \\
\hline D13S317 & 11,13 & $\mathbf{1 1 , 1 3}$ & $\mathbf{1 1 , 1 3}$ \\
\hline D16S539 & 10,13 & $\mathbf{1 0 , 1 3}$ & $\mathbf{1 0 , 1 3}$ \\
\hline D18S51 & 17 & $\mathbf{1 7}$ & $\mathbf{1 7}$ \\
\hline CSF1P0 & 11,13 & $\mathbf{1 1 , 1 3}$ & $\mathbf{1 1 , 1 3}$ \\
\hline TH01 & $8,9.3$ & $\mathbf{8 , 9 . 3}$ & $\mathbf{8 , 9 . 3}$ \\
\hline vWA & 16,19 & $\mathbf{1 6 , 1 9}$ & $\mathbf{1 6 , 1 9}$ \\
\hline D21S11 & $30.2,31$ & $\mathbf{3 0 . 2 , 3 1}$ & $\mathbf{3 0 . 2 , 3 1}$ \\
\hline D5S818 & 12,13 & $\mathbf{1 2 , 1 3}$ & $\mathbf{1 2 , 1 3}$ \\
\hline D7S820 & 9,12 & $\mathbf{9 , 1 2}$ & $\mathbf{9 , 1 2}$ \\
\hline TPOX & 8,9 & $\mathbf{8 , 9}$ & $\mathbf{8 , 9}$ \\
\hline D8S1179 & 13,14 & $\mathbf{1 3 , 1 4}$ & $\mathbf{1 3 , 1 4}$ \\
\hline FGA & 25,26 & $\mathbf{2 5 , 2 6}$ & $\mathbf{2 5 , 2 6}$ \\
\hline AMEL & $\mathrm{X}$ & $\mathrm{X}$ & $\mathrm{X}$ \\
\hline
\end{tabular}

Bold: in accordance with the published STR profiles of ATCC IMR-90 (ATCC ${ }^{\circledR}$ CCL-186 ${ }^{\mathrm{TM}}$ ) original lung fibroblasts, which IMR90 iPSCs were generated from (Cellosaurus CVCL_0347, n.d.).x

should be considered. In our case, we decided against this as Life-Act-eGFP cells were made from an IMR90 C4 WCB, so their STR analysis result therefore also proved the correct identity of the IMR90-C4 WCB.

\subsection{Cytogenetic analysis by classical G-banding (assay 4)}

Certain types of aneuploidy have been recurrently identified in hiPSC cultures, including partial or complete gain of chromosome $8,12,17$, or 20 , trisomy $\mathrm{X}$, and chromosome 1 amplification (Mayshar et al., 2010; Amps et al., 2011; Taapken et al., 2011; Kilpinen et al., 2017; Assou et al., 2018). Therefore, it is important to analyze the genetic stability of a given hiPSC line. Ideally, the technique of choice for this should be inexpensive, yield fast results, and have high resolution and sensitivity, but, unfortunately, this all-in-one solution does not exist (Assou et al., 2018). Nevertheless, different techniques are available: fluorescent in situ hybridization (FISH), array comparative genomic hybridization (aCGH), SNP arrays, next-generation sequencing, quantitative PCR, and G-banding karyotype analysis 


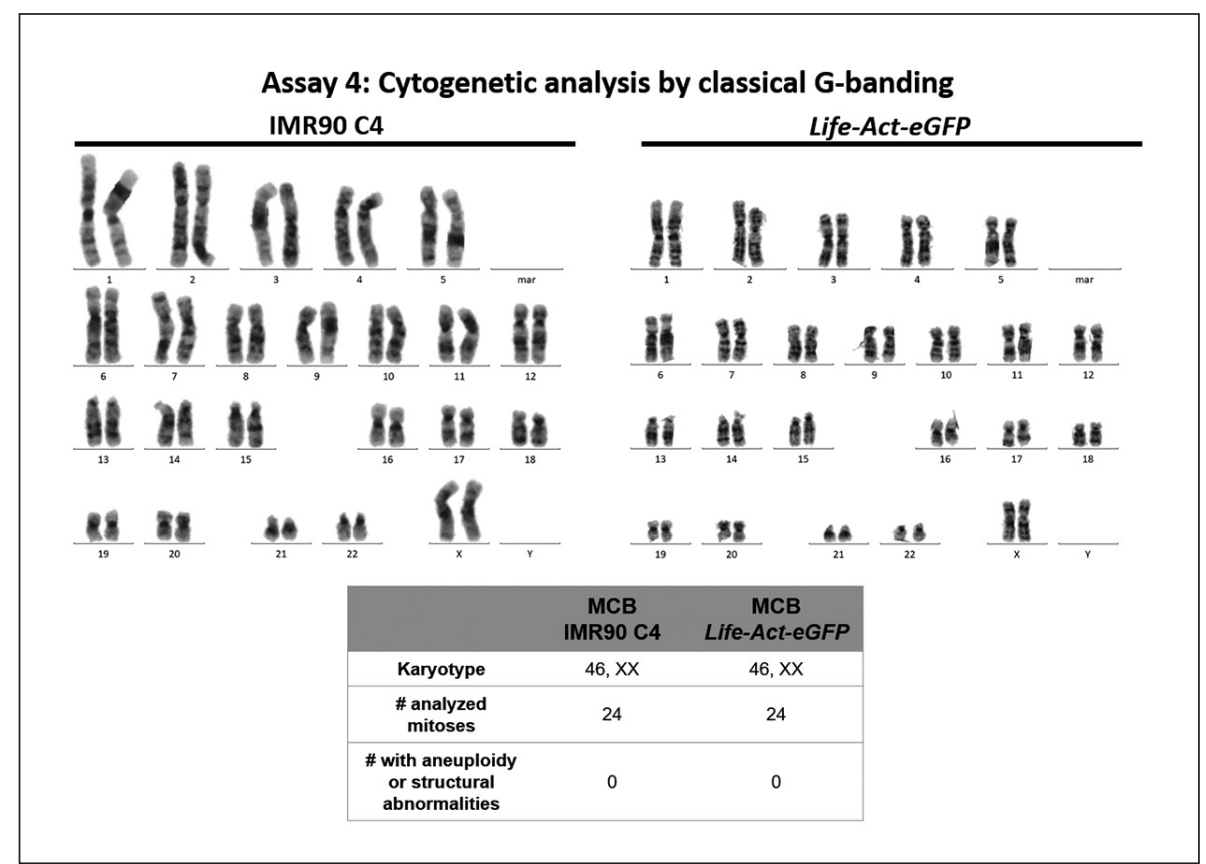

Fig. 4: Results of cytogenetic analysis by classical G-banding (assay 4) 24 mitoses for each MCB (IMR90-C4 and Life-Act-eGFP) were prepared and analyzed for aneuploidy or structural abnormalities using classical G-banding. Representative images of chromosomes are shown for each line, and results are summarized in the table.

(Assou et al., 2018). While FISH analysis reliably identifies additional attributable chromosomal material (e.g., marker chromosomes), it has a resolution limit of $>1-2 \mathrm{Mb}$ (MacArthur et al., 2014), only detecting larger abnormalities. CGH, SNP arrays, and whole genome sequencing on the other hand are extremely sensitive methods, capable of detecting chromosomal regions as small as $25 \mathrm{kbs}$ as well as mosaicism (Conrad et al., 2010; Yaffe et al., 2016), but until recently were not able to detect inversions or balanced rearrangements (O'Shea et al., 2020). This has changed with technological progress, resulting in long reads (up to $60 \mathrm{kbs}$ ), which allow the detection of both inversions and rearrangements (Bartalucci et al., 2019; Zhang et al., 2019; Lei et al., 2020). Nevertheless, another drawback of these high-resolution methods is that while they provide a lot of data, they lack a definition of what differences may impact the reproducibility of research (Kleensang et al., 2016). Commercially available qPCR analysis kits, which detect the majority of karyotypic abnormalities reported in human ES and iPS cells, have the great disadvantage of bias: You only detect, what you look for. We believe that this method is to be preferred over not analyzing the cells at all, but it might create a false security compared to the other discussed unbiased approaches. ISCBI suggests using standard G-banding analysis, which can identify trisomy and gross chromosomal duplications/deletions and translocations. It is also the only major method that can detect structural abnormalities such as balanced translocations or inversions (Ntai et al., 2017; Rohani et al., 2018). According to ISCBI, a count of 20 metaphases and the analysis of the banding pattern of at least 8 metaphases (Bickmore, 2001; Loring et al., 2007; ISCBI, 2009) should be performed. $95 \%$ of the analyzed metaphases should hereby possess a normal karyotype (Pamies et al., 2017). Identified chromo- somal abnormalities of clonal origin should be confirmed in an independent analysis. Abnormalities in single cells could be due to a technical artefact but could also point towards a beginning clonal abnormality or low-level mosaicism (Hook, 1977; Sikkema-Raddatz et al., 1997). Here, again, a repeated analysis is suggested to allow interpretation of the results. In cooperation with the Institute of Human Genetics at the University Clinic Duesseldorf, we analyzed the chromosomes of 24 metaphase spreads, none of them displaying any abnormalities (Fig. 4).

It is important to note that the analysis of genomic stability, regardless of the chosen method, is only a current snapshot, and it has been reported that a genetically abnormal clone can completely overtake a culture (Baker et al., 2007) in less than five passages (Bai et al., 2013). Therefore, others have proposed to test for genomic integrity on a regular basis, at least every 12 weeks (WHO, 2013; Assou et al., 2018) or every 15 passages (WHO, 2013; Pamies et al., 2017). To bypass this laborious and time-intensive G-banding analysis every 12 weeks, we analyze hiPSC at the time of banking and culture them after thawing for only 8 passages in total (ca. 6 weeks), i.e., three passages to ensure full recovery after cryoconservation plus 5 passages for use in different assays. Hence, our cells never reach 15 passages or 12 weeks in culture.

\subsection{Expression of stem cell markers on protein (assay 5) and mRNA (assay 6) level}

Commonly used characterization methods to assess the self-renewal capacity of hiPSCs include immunocytochemical staining for alkaline phosphatase and intracellular markers (Nanog, POUF1, GDF3, DNMT3B), identification of cell surface stem cell markers (SSEA3, SSEA4, TRA-1-60, TRA-1-81) via flow 


\section{Assay 5: Cell Antigen Expression \& Cell Count/Viability}
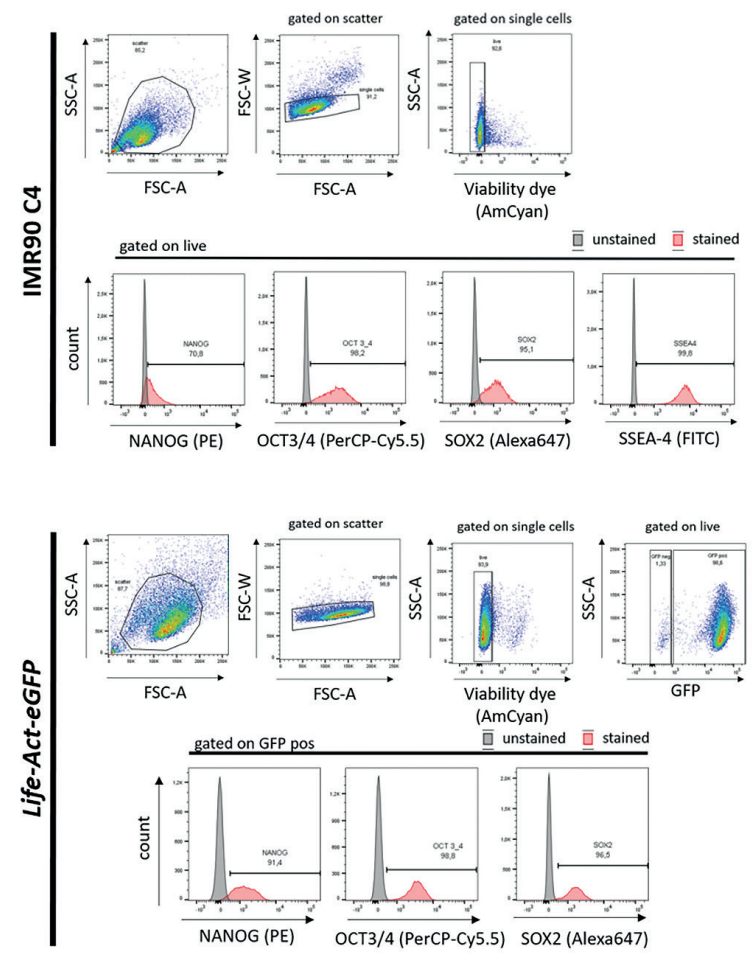

Assay 6: Cell Gene Expression

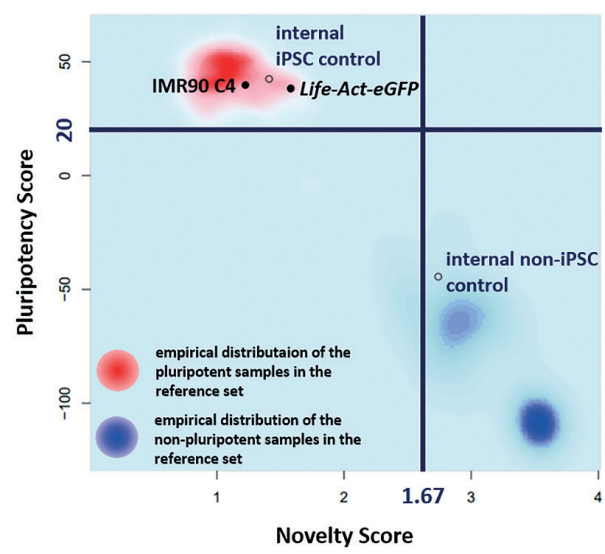

\begin{tabular}{|cccc|}
\hline IMR90 C4 & $\begin{array}{c}\text { Pluriptency } \\
\text { Score }\end{array}$ & $\begin{array}{c}\text { Novelty } \\
\text { Score }\end{array}$ & $\begin{array}{c}\text { PluriTest } \\
\text { Result }\end{array}$ \\
\hline Life-Act-eGFP & 38.31 & 1.23 & Pass \\
\hline $\begin{array}{c}\text { Internal iPSC } \\
\text { control }\end{array}$ & 42.46 & 1.41 & Pass \\
\hline $\begin{array}{l}\text { Internal non- } \\
\text { IPSC control }\end{array}$ & -44.43 & 2.74 & Fail \\
\hline
\end{tabular}

Fig. 5: Results of cell antigen expression and cell count/viability (assay 5) and cell gene expression (assay 6)

Assay 5: Cell antigen expression assessed by multipanel flow cytometric analysis for the stem cell markers Nanog-PE, OCT3/4-PerCPCy5.5, Sox2-Alexa Fluor 647, and SSEA-4-FITC (assay \#5.1) plus Fvs 510 (AmCyan; assay \#5.2) as live/dead discriminator. Acquisition and analysis were performed on a BD FACSCanto ${ }^{\text {TM }}$ II system using BD FACS Diva Software Version 6.1.3. Analysis was performed using Flow Jo V10.7.1. Assay 6: Cell gene expression assessed by the PluriTest ${ }^{\mathrm{TM}}$ assay (assay \#6) as pluripotency plot. Transcriptomes of MCBs IMR90-C4 (upper panel) and Life-Act-eGFP (lower panel) were analyzed and processed in the PluriTest ${ }^{\mathrm{TM}}$ algorithm to generate pluripotency and novelty score. Depicted are pluripotency score (y-axis) and novelty score (x-axis). The red and blue background visualize the empirical distribution of the pluripotent (red) and non-pluripotent (blue) samples in the reference dataset. A non-iPSC sample was included in this experiment to serve as a control for non-pluripotency.

cytometry, and assessment of OCT4 and Sox 2 expression in a lineage commitment assay (Pamies et al., 2017). While all of these methods and markers are widely accepted and commonly used, a standardized set of markers has yet to be established (Pamies et al., 2017). We choose to use a commercially available FACS antibody kit for stem cell transcription factors to analyze the expression of stem cell markers on the protein level at the time of banking. This ensures a quantitative outcome, a relatively easy establishment in the laboratory, and includes three markers of the standard human pluripotent stem cell (hPSC) panel, OCT3/4, Sox2, and Nanog, of which an analysis of at least two has been stated as mandatory (Sullivan et al., 2018). It also yields the possibility to expand the assay for an additional canonical cell surface marker, in our case SSEA-4, which has also been proposed (Pamies et al., 2017; Sullivan et al., 2018). Performing the analysis for our MCBs revealed that although OCT3/4,
Sox2, and SSEA-4 were all expressed in well above $95 \%$ of the IMR90-C4 MCB cells cultivated on LN521 (98.2, 96.3, and $99.9 \%$ ), Nanog expression fell short of the quality criterion of $>70 \%$ marker expression (Pamies et al., 2017; Sullivan et al., 2018; Fig. S1 ${ }^{2}$ ). When the cultivation conditions were changed to MG and mTeSR medium (according to 2.1.2.4), expression of OCT3/4, Sox2, and SSEA-4 remained at the high level observed on LN521 (98.2, 95.1, and 99.8\%, respectively), but Nanog was now expressed in $70.8 \%$ of the cells (Fig. 5; left, upper panel), indicating the influence of the chosen culturing conditions on hiPSC performance. This observation is supported by others, who already stated that there is no "one-fits-all" culture method that provides optimal conditions for all hiPSC lines (Christensen et al., 2018). With these results in mind, Life-Act-eGFP cells were directly cultured and banked on MG and expressed Nanog (91.4\%), OCT3/4 (98.8\%) and Sox2 (96.5\%) (Fig. 5; left, 


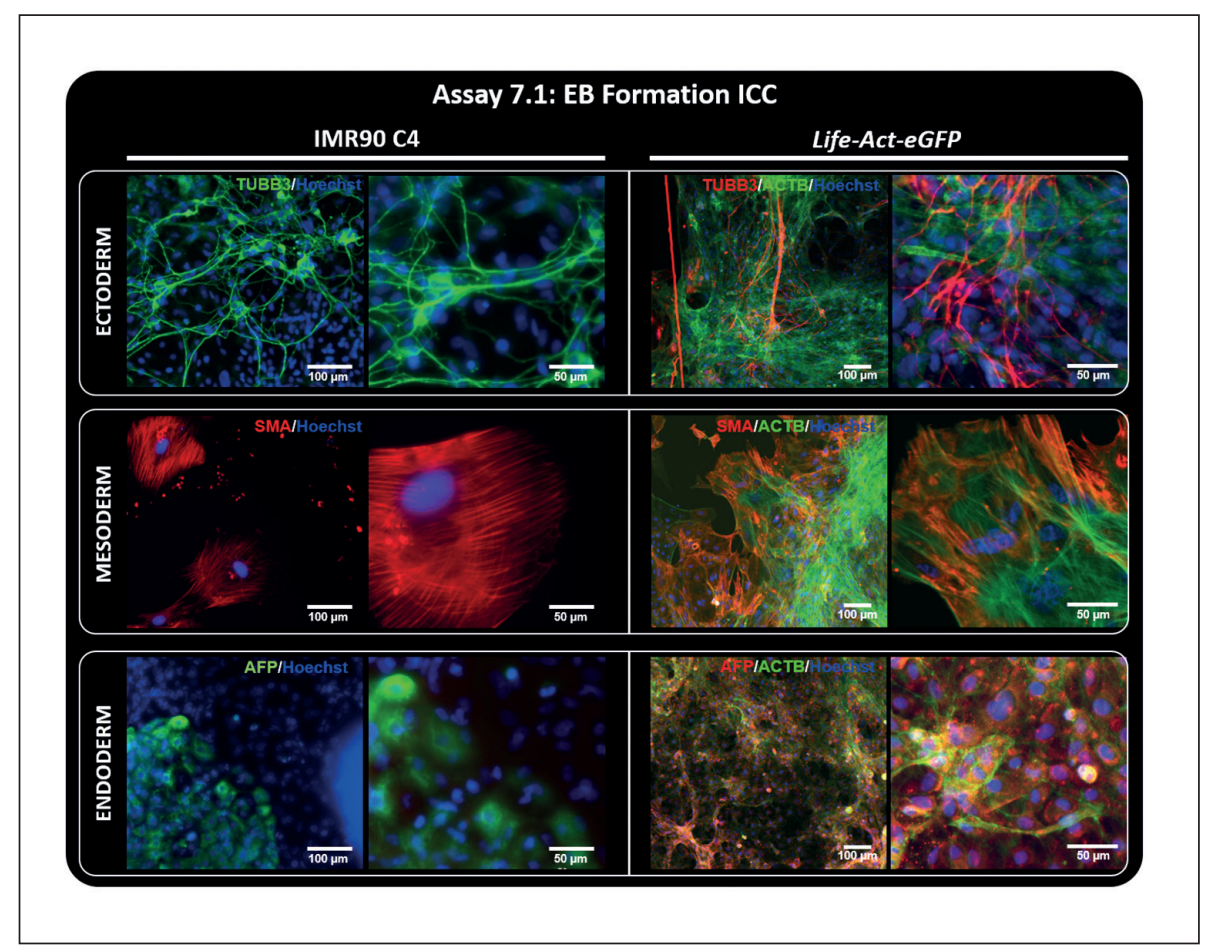

Fig. 6: Results of EB formation assessed by immunocytochemistry (assay 7.1)

Representative immunofluorescent images of plated EBs of the MCBs of IMR90-C4 (left) and Life-ActeGFP (right). EBs were generated, differentiated under proliferating conditions for 7 days, and then plated on gelatin-coated 24-well plates and fixed after 7 and 14 days of differentiation. Cells were stained for markers of the three germ layers: $\beta$ (III) tubulin (TUBB3) for ectoderm, smooth muscle actin (SMA) for mesoderm and a-feto protein (AFP) for endoderm. All images were taken from cells fixed on day 14 after plating, except for IMR90-C4 TUBB3, which represents day 7 .

lower panel). We wish to point out that using animal-free matrices is highly desirable, yet such matrices need to be shown to yield comparable results to Matrigel. Note that SSEA-4 expression was not analyzed, as $98.6 \%$ of the Life-Act-eGFP cells express GFP, which is detected in the same channel as the SSEA4FITC antibody. Using a different fluorochrome for this marker might be an option for future analyses. Cell viability assessed using Fvs 510 was at 92.6 and $93.9 \%$ for IMR90-C4 and Life-Act$e G F P$, respectively (Fig. 5; left).

To assess the expression of stem cell markers on mRNA level, we chose the commercially available PluriTest ${ }^{\mathrm{TM}}$ assay (Müller et al., 2011), which is a high-density microarray comparing the transcriptome of a test cell line to that of a large number of known pluripotent cell lines (ISCI, 2018). It is not able to account for heterogeneous cell populations (D'Antonio et al., 2017) and is therefore restricted to the assessment of self-renewal patterns (Pamies et al., 2017). Nevertheless, this assay provides valid insights into the stem cell character of cells based on a large number of analyzed genes (D'Antonio et al., 2017). Cell gene expression analyses of our banked hiPSC lines assessed by the PluriTest ${ }^{\mathrm{TM}}$ assay revealed that both cluster with the pluripotent samples in the reference set and yield a pluripotency score (PS) of 39.83 and 38.31 and a novelty score (NS) of 1.23 and 1.58 for IMR90-C4 and LifeAct-eGFP, respectively (Fig. 5; right). This is well within the range of the defined threshold values of $>20$ for PS, indicating that the samples are more similar to the pluripotent samples of the reference set than to the other samples, and $<1.67$ for NS, demonstrating that the tested samples can be well reconstructed based on existing data from other well-characterized iPSC and ESC lines established for this assay (Müller et al., 2011; Müller, 2014).

\subsection{Assessment of pluripotency (assay 7)}

While the in vivo teratoma assay identifying cell types of ectodermal, mesodermal and endodermal origin using $\mathrm{H} / \mathrm{E}$ stained histological sections is still considered to be the gold standard for pluripotency assessment of a given hPSC line, it holds the ethical burden of animal testing (Gertow et al., 2007; Gropp et al., 2012; Pamies et al., 2017), is cost- and time-intensive, is associated with reproducibility problems, and requires special expertise (ISCBI, 2009). Therefore, alternative, low-burden, high-throughput molecular methods are on the rise $\mathrm{Bu}-$ ta et al., 2013; Pamies et al., 2017). While also other methods, e.g., directed differentiation (Borowiak et al., 2009; Chambers et al., 2009; Kattman et al., 2011; Burridge et al., 2012) exist, positive detection of trilineage specific markers (e.g., SMA for mesoderm, TUBB3 for ectoderm, and AFP for endoderm) in spontaneously differentiating EBs is an accepted method to verify the pluripotency of PSCs (Sathananthan and Trounson, 2005; de Miguel et al., 2010; Pistollato et al., 2012). As suggested by ISCI (2018), we chose to combine in vitro spontaneous EB differentiation with bioinformatic Scorecard ${ }^{\mathrm{TM}}$ analyses. This commercially available assay is a medium/low density focused array that compares lineage expression levels to a reference standard (Pamies et al., 2017), thereby confirming (i) the self-renewal capacity and (ii) the trilineage differentiation potential of an hiPSC line (Bock et al., 2011). Alternatively, it is an option to perform an in-house qPCR assay on the EBs, as suggested by O'Shea and co-workers (2020), analyzing three to five markers for each germ layer. However, we believe that the additional information provided by the Scorecard ${ }^{\mathrm{TM}}$ assay justifies the additional costs and effort. 


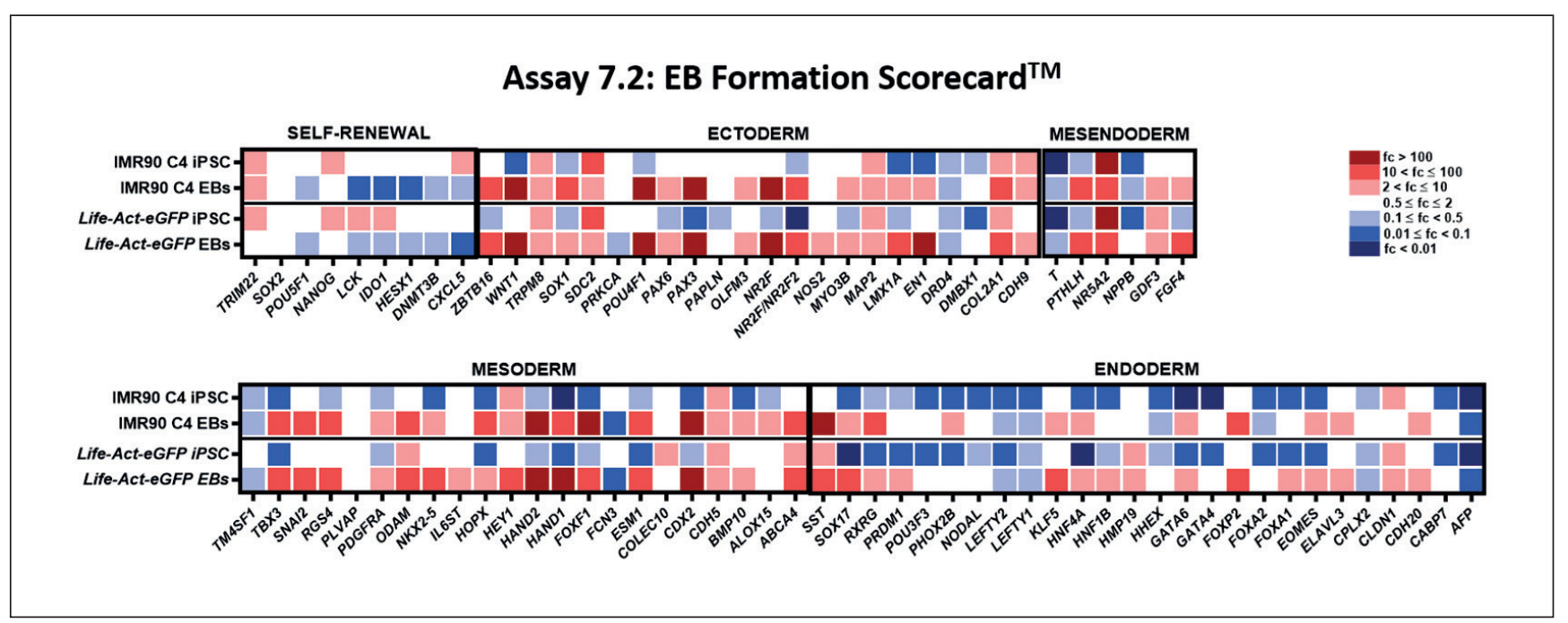

Fig. 7: Results of EB formation assessed by the Scorecard ${ }^{\mathrm{TM}}$ assay (assay 7.2) for MCBs of IMR90-C4 (upper panel) and Life-Act-eGFP (lower panel)

EBs were generated and cultured under proliferating conditions for 7 days before cell pellets were collected for analysis. The respective undifferentiated hiPSCs serve as undifferentiated controls. Colors correlate with the fold-change in expression of the indicated gene relative to the undifferentiated reference set.

Following this approach, ICC analyses of differentiated EBs of both analyzed hiPSC lines revealed that cells of both MCBs were able to spontaneously differentiate into cells expressing marker proteins for the three germ layers: TUBB3 for ectoderm, SMA for mesoderm, and AFP for endoderm (Fig. 6). Additional Score$\operatorname{card}^{\mathrm{TM}}$ gene expression analyses verified these findings. Whereas marker genes for self-renewal such as TRIM22 and Nanog were upregulated in undifferentiated hiPSCs of both MCBs, they were downregulated in the respective EBs, and at the same time marker genes for ectoderm, mesendoderm, mesoderm and endoderm were upregulated compared to the undifferentiated reference set (Fig. 7). Comparing the level of gene induction between the different germ layers, it is noticeable that while still upregulated compared to the undifferentiated hiPSCs, expression levels of endodermal markers seem to be lower (with the exception of SST for the IMR90 C4 cells, they are in the range of 10 to 100 -fold induction) than expression of markers for ectoderm and mesoderm. Here, overall, more markers are upregulated, some also to over 100 -fold. This might indicate that both analyzed hiPSC lines are less prone to differentiate into cells of the endodermal lineage.

\subsection{Post-thaw recovery assessment (assay 8)}

It has been reported that a post-thaw recovery assessment directly at the time of thawing might be misleading regarding the integrity of the cells (Pamies et al., 2017), therefore we chose to analyze the banked cells when they were split the first time after thawing and assessed the confluency of the colonies, cell morphology, and percentage of living cells.

We are aware that hiPSCs are affected by cryopreservation and thawing, which can lead to changes in cell morphology and altered proliferation behavior in the first passage after cryopreservation (Archibald et al., 2016). Nevertheless, we believe it is im- portant to assess the morphology of the thawed cells to get an idea of the quality of the banked cells. Later, cells are monitored on a daily basis and used for experiments only after a recovery period of three passages and with a morphology score of A.

To assess post-thaw recovery of the MCB vials, one vial each for IMR90-C4 and Life-Act-eGFP was thawed and cultivated until the cells reached approx. $70 \%$ confluency and needed passaging for the first time post thawing (p.t.). For IMR90-C4 this was on day 3 p.t. and for Life-Act-eGFP on day 2 p.t. The cultures were assessed microscopically (Fig. 8, right) and displayed characteristic stem cell morphology. Furthermore, the percentage of living cells was assessed using the trypan blue exclusion assay (Fig. 8, left), revealing 92\% living cells for IMR90-C4 and $77.5 \%$ for Life-Act-eGFP.

\subsection{Assay costs}

All too often, QC assays are not regularly applied in academic labs, as the costs are believed to be high and, frankly speaking, it is commonly difficult to get such work financed by third party funding. Nevertheless, we argue that the benefit of performing QC assays resulting in high quality cell material, which is a prerequisite for reproducible data, by far outweighs the financial burden. To promote the integration of QC work into academic research projects, we have calculated the costs for the generation of quality controlled MCBs and WCBs.

A standard MCB of 50 vials with all eight QC assays described here totals approximately $2340 €$ (Tab. 3). Every additional WCB of 50 vials with 5 QC-assays will cost about another $1000 €$. Let's make a simple theoretical calculation: One MCB of 50 vials (2340€ in total, $46.80 € /$ vial) yields $50 \mathrm{WCBs}$ with 50 individual vials each $(\sim 21.20 € /$ vial, considering the MCB vial that is needed to generate these WCBs), resulting in 2500 vials 
Assay 8: Trypan Blue Exclusion
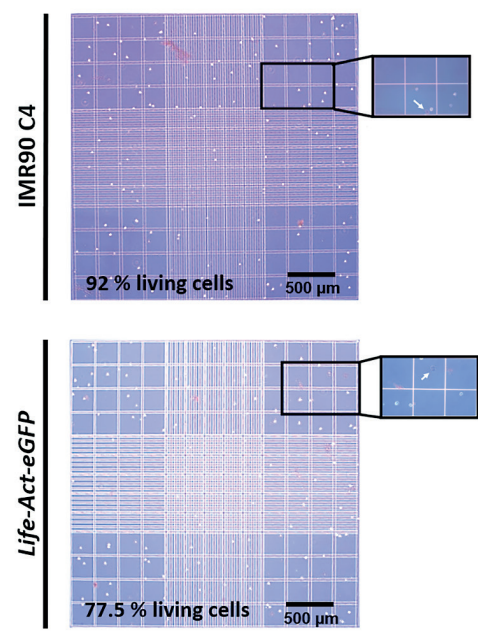

\section{Assay 8: Microscopic Assessment}

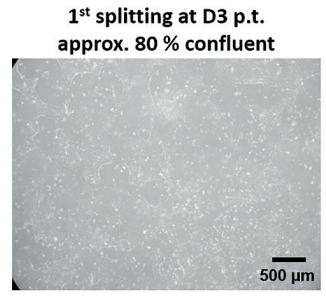

$1^{\text {st }}$ splitting at D2 p.t.

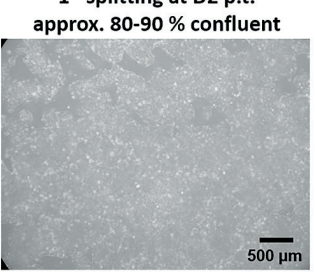

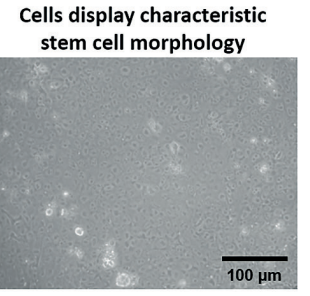

Cells display characteristic stem cell morphology

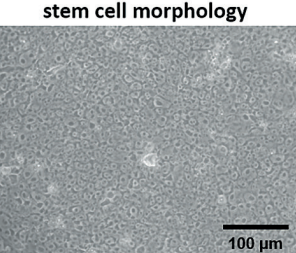

Fig. 8: Results of trypan blue exclusion assay and microscopic assessment for post-thaw recovery testing (assay 8) of MCBs from IMR90-C4 (upper panel) and Life-Act-eGFP (lower panel) at the $1^{\text {st }}$ split after re-thawing (D3 for IMR90-C4, D2 for Life-Act-eGFP)

Left: Results of trypan blue exclusion assay. Right: Representative images of the respective cultures showing the density of the cultures (40x magnification) as well as the stem cell morphology of the cells (200x magnification). p.t., post thaw; D, day

Tab. 3: Estimated costs for a MCB of 50 vials including all suggested assays for quality control A short summary of included techniques and analyses is included in brackets. Average costs are listed, with lowest and highest costs in brackets. Please note that this list is probably not complete and should only give a gross estimate of the costs. Not included are personnel costs, standard plastic ware, EtOH, pipette tips, etc. Procedures/assays that need to be performed for both MCB and WCB are indicated in blue italic font.

\begin{tabular}{|c|c|c|}
\hline Assay \# & Assay & $\begin{array}{l}\text { Average costs/MCB ( } 50 \text { vials) }(€) \\
\text { (lowest and highest costs) }\end{array}$ \\
\hline & Culturing costs from thawing to MCВ (Matrigel, medium, EDTA) & 509.45 \\
\hline & Cryopreservation (cryovials, EDTA, cryopreservation medium) & 220.41 \\
\hline 1 & Colony morphology & n.a.c. \\
\hline 2 & Mycoplasma PCR & 34.83 \\
\hline 3 & STR genotyping (gDNA isolation, STR analysis) & $72.94(25.87-120)$ d.o.p. \\
\hline 4 & Karyotype analysis & $150.00(0-300)$ d.o.p. \\
\hline 5.1 & $\begin{array}{l}\text { FACS analysis of stem cell markers (FACS kit, additional SSEA-4 antibody, } \\
\text { and isotype control) }\end{array}$ & 143.30 \\
\hline 5.2 & Cell count and viability (fixable viability stain for FACS analysis) & 2.91 \\
\hline 6 & PluriTest $^{\mathrm{TM}}$ & 283.90 \\
\hline 7 & $\begin{array}{l}\text { EB formation (culture dishes, gelatine solution, medium, PBS with and } \\
\text { w/o } \mathrm{Ca}^{2+} \text { and } \mathrm{Mg}^{2+}, \text { EDTA) }\end{array}$ & 188.04 \\
\hline 7.1 & $\begin{array}{l}\text { ICC of EBs (PBS with } \mathrm{Ca}^{2+} \text { and } \mathrm{Mg}^{2+}, \mathrm{BSA} \text {, Tween } 20 \text {, Hoechst } 33258 \text {, } \\
\text { first antibodies against AFP, SMA and TUBB3, secondary antibody) }\end{array}$ & 132.52 \\
\hline 7.2 & Scorecard ${ }^{\mathrm{TM}}$ & 601.70 \\
\hline \multirow[t]{2}{*}{8} & Post-thaw recovery assessment & n.a.c. \\
\hline & Total costs & $\begin{array}{l}2340 \\
(2142.93-2537.06)\end{array}$ \\
\hline
\end{tabular}

n.a.c., no additional costs; d.o.p., depending on provider 
Tab. 4: Overview of proposed QC assays and respective specifications for hiPSC

Assays (assay \#) are numbered consecutively. Procedures/assays that need to be performed for both MCB and WCB are indicated in blue italic font. Release criteria represent acceptance criteria for further use of hiPSCs.

\begin{tabular}{|c|c|c|c|}
\hline Information about & QC assay \# & Proposed characterization assay & Release criteria \\
\hline $\begin{array}{l}\text { Colony/cell } \\
\text { morphology }\end{array}$ & 1 & $\begin{array}{l}\text { Microscopic assessment at time of banking } \\
\text { (+ daily assessment) }\end{array}$ & $\begin{array}{l}\text { Characteristic stem cell morphology (see 2.2); } \\
\text { lack of spontaneously differentiated cells }\end{array}$ \\
\hline Mycoplasma & 2 & Mycoplasma PCR & No contamination detected \\
\hline Identity & 3 & STR genotyping (gDNA isolation, STR analysis) & Shares all alleles of parent line \\
\hline Karyotype & 4 & Classical G-banding & $\begin{array}{l}\text { Normal diploid karyotype (without clonal } \\
\text { aberrations; single aberrations in 5\% of the } \\
\text { analyzed metaphase spreads are acceptable) }\end{array}$ \\
\hline \multirow[t]{3}{*}{$\begin{array}{l}\text { Expression } \\
\text { of stem-cell } \\
\text { markers }\end{array}$} & 5.1 & $\begin{array}{l}\text { Cell antigen expression: flow cytometric } \\
\text { analysis of stem cell markers SSEA-4, OCT3/4, } \\
\text { NANOG, SOX2 }\end{array}$ & $>70 \%$ expression of all analyzed markers \\
\hline & 5.2 & $\begin{array}{l}\text { Cell count and viability (fixable viability stain, } \\
\text { flow cytometric analysis) }\end{array}$ & $>80 \%$ viable cells at time of banking \\
\hline & 6 & Cell gene expression: PluriTest ${ }^{\mathrm{TM}}$ & Analyzed cells cluster with hPSC reference \\
\hline \multirow[t]{2}{*}{ Pluripotency } & 7.1 & EB formation: ICC & $\begin{array}{l}\text { At least one marker of each germ layer is } \\
\text { detectable }\end{array}$ \\
\hline & 7.2 & EB formation: Scorecard ${ }^{\mathrm{TM}}$ & \\
\hline \multirow[t]{4}{*}{$\begin{array}{l}\text { Post-thaw } \\
\text { recovery }\end{array}$} & 8 & $\begin{array}{l}\text { Trypan blue exclusion assay, microscopic } \\
\text { assessment }\end{array}$ & $\begin{array}{l}\text { Assessed at } 1^{\text {st }} \text { splitting after thawing } \\
\text { (max. } 7 \text { days) }\end{array}$ \\
\hline & & & $>70 \%$ living cells \\
\hline & & & $>70 \%$ confluency \\
\hline & & & Characteristic stem cell morphology \\
\hline
\end{tabular}

costing $22.15 €$ each $(21.20 €+(46.80 € / 50))$. To ensure working with hiPSCs for experiments in passage 4-8, we thaw one vial every 4 weeks (12 per year), leading to pure cell costs of approx. $266 €$ per year $(22.15 € \times 12)$. This is by far less than the cost of your average commercially available hiPSC line. In this scenario, these $2.500 \mathrm{WCB}$ vials would be sufficient to provide the laboratory with quality-controlled cell material for a little over 208 years $(2.500 / 12)$.

We strongly believe that these numbers speak for themselves: Although the initial investment seems high, in the long run using quality-controlled cell material as a starting point for any research question pays off!

\section{Summary and conclusion}

Human iPSCs are a promising tool to replace animal experiments for toxicity testing and other research questions. However, there is international consensus that only quality controlled cell material ensures reproducibility of data. Due to a lack of specific "handson" guidance on hiPSC QC in an academic research environment, we have assembled a set of assays that warrants hiPSC identity, genomic stability, and pluripotency by assessment of cell/colony morphology (assay 1), mycoplasma contamination (assay 2), cell line identity (assay 3), karyotype stability (assay 4), cell antigen expression and viability (assays $5.1+5.2$ ), cell gene expression (assay 6), pluripotency (assays 7.1 +7.2 ), and post-thaw recovery (assay 8; Tab. 4) for the two hiPSC lines IMR90-C4 and LifeAct-eGFP (Fig. 9). Of note, these assays are intended for hiPSC lines accessed from external sources such as commercial vendors or iPSC biobanks. Additional QC, e.g., viral clearance assays, are necessary if researchers generate their own iPSC lines from primary human material. Furthermore, additional QC assays might be appropriate for genetically modified hiPSC lines, e.g., the assessment of viral clearance in case of the use of viral vectors. Using these or similar QC assays in the context of a two-tieredbanking approach consisting of one MCB per hiPSC line and respective WCBs provides researchers with reliable cell material for hiPSC-based applications, thereby safeguarding high hiPSC quality at all times. Our calculations demonstrate the financial feasibility of such an approach in an academic research set-up.

We conclude that an international consensus on QC for stem cell-based academic research, e.g., the strategy followed in this article, is highly warranted. Awareness of funding agencies and journals of QC as a requirement when sponsoring or publishing stem cell research is desirable for improving the current reproducibility crisis in cell-based research. This will not only produce more reliable and reproducible results in basic research but will also strongly support the application and decrease the uncertainty of stem cell-based methods in applied sciences like regulatory toxicology. 

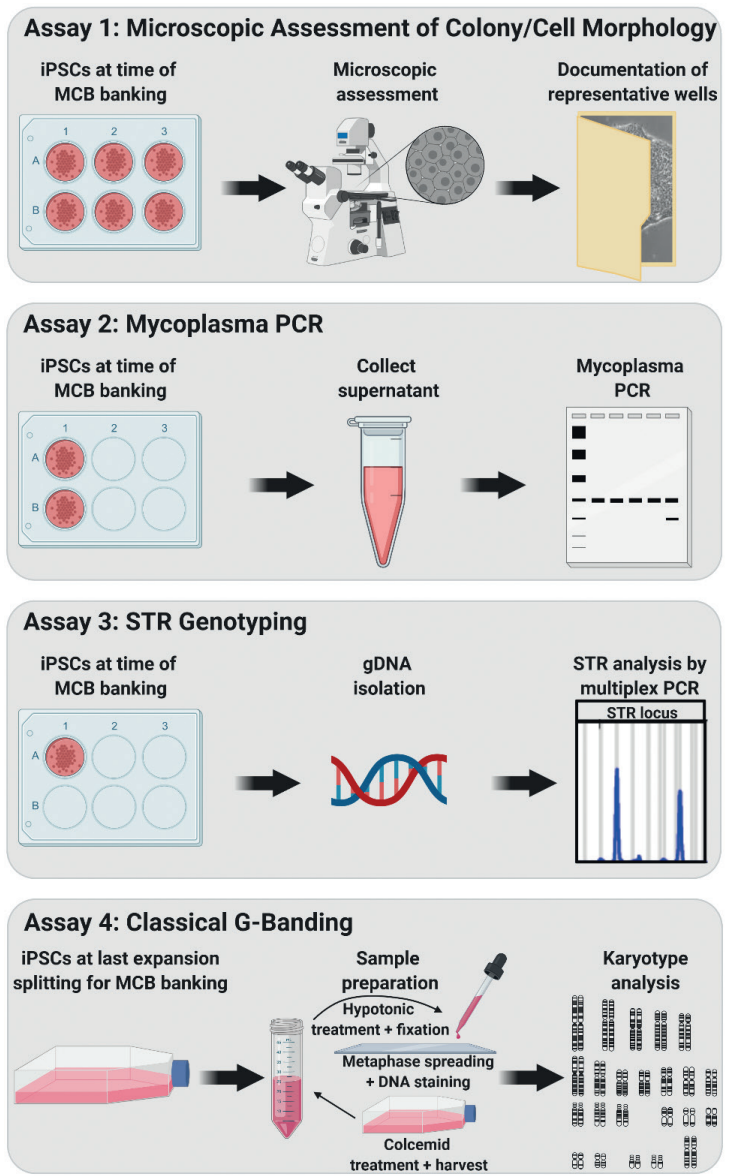
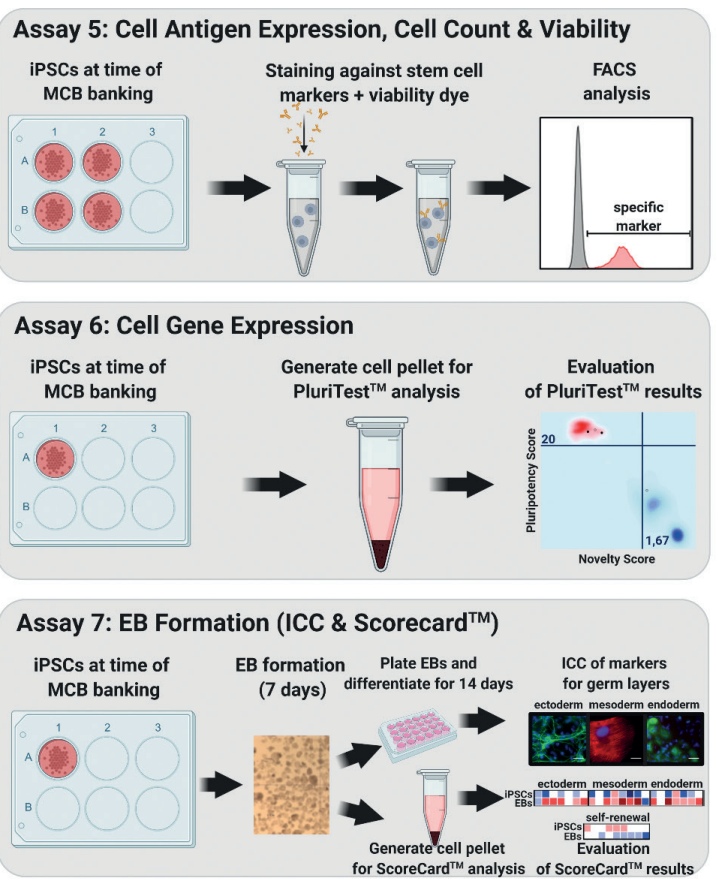

Assay 8: Trypan Blue Exclusion \& Microscopic Assessment

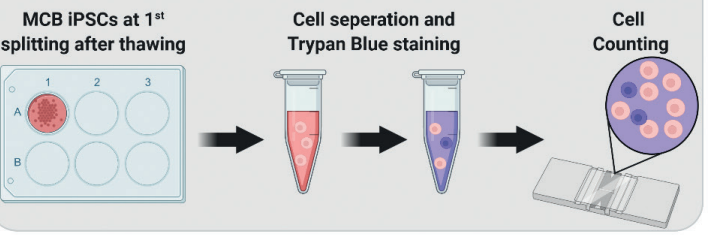

Fig. 9: Summary of proposed quality control assays for iPSC in an academic research laboratory

\section{References}

Abbot, S., Agbanyo, F., Ahlfors, J. E. et al. (2018). Report of the international conference on manufacturing and testing of pluripotent stem cells. Biologicals 56, 67-83. doi:10.1016/j. biologicals.2018.08.004

Adler, S., Allsopp, T., Bremer, S. et al. (2007). hESC Technology for Toxicology and Drug Development: Summary of Current Status and Recommendations for Best Practice and Standardization The Report and Recommendations of and ECVAM Workshop.

Almeida, J. L., Cole, K. D. and Plant, A. L. (2016). Standards for cell line authentication and beyond. PLoS Biol 14, e1002476. doi:10.1371/journal.pbio.1002476

Amps, K., Andrews, P. W., Anyfantis, G. et al. (2011). Screening ethnically diverse human embryonic stem cells identifies a chromosome 20 minimal amplicon conferring growth advantage. Nat Biotechnol 29, 1132-1144. doi:10.1038/nbt.2051

Andrews, P. W., Baker, D., Benvinisty, N. et al. (2015). Points to consider in the development of seed stocks of pluripotent stem cells for clinical applications: International stem cell banking initiative (ISCBI). Regen Med 10, Suppl 2, 1-44. doi:10.2217/ rme.14.93

Archibald, P. R. T., Chandra, A., Thomas, D. et al. (2016). Comparability of automated human induced pluripotent stem cell culture: A pilot study. Bioprocess Biosyst Eng 39, 1847-1858. doi:10.1007/s00449-016-1659-9

Armstrong, S. E., Mariano, J. A. and Lundin, D. J. (2010). The scope of mycoplasma contamination within the biopharmaceutical industry. Biologicals 38, 211-213. doi:10.1016/j. biologicals.2010.03.002

Assou, S., Bouckenheimer, J. and De Vos, J. (2018). Concise review: Assessing the genome integrity of human induced pluripotent stem cells: What quality control metrics? Stem Cells 36, 814-821. doi:10.1002/stem.2797

Baghbaderani, B. A., Tian, X., Neo, B. H. et al. (2015). CGMPmanufactured human induced pluripotent stem cells are available for pre-clinical and clinical applications. Stem Cell Reports 5, 647-659. doi:10.1016/j.stemcr.2015.08.015 
Bai, Q., Desprat, R., Klein, B. et al. (2013). Embryonic stem cells or induced pluripotent stem cells? A DNA integrity perspective. Curr Gene Ther 13, 93-98. doi:10.2174/1566523211313020003

Bairoch, A. (2018). The cellosaurus, a cell-line knowledge resource. J Biomol Tech 29, 25-38. doi:10.7171/jbt.18-2902-002

Baker, D. E. C., Harrison, N. J., Maltby, E. et al. (2007). Adaptation to culture of human embryonic stem cells and oncogenesis in vivo. Nat Biotechnol 25, 207-215. doi:10.1038/nbt1285

Baker, M. (2016). How quality control could save your science. Nature 529, 456-458. doi:10.1038/529456a

Baker, M. and Penny, D. (2016). Is there a reproducibility crisis? Nature 533, 452-454. doi:10.1038/533452A

Bartalucci, N., Romagnoli, S., Contini, E. et al. (2019). Long reads, short time: Feasibility of prenatal sample karyotyping by nanopore genome sequencing. Clin Chem 65, 1605-1608. doi:10.1373/clinchem.2019.310805

Bickmore, W. A. (2001). Karyotype analysis and chromosome banding. In Encyclopedia of Life Sciences. Chichester, UK: John Wiley \& Sons, Ltd. doi:10.1038/npg.els.0001160

Bock, C., Kiskinis, E., Verstappen, G. et al. (2011). Reference maps of human ES and iPS cell variation enable high-throughput characterization of pluripotent cell lines. Cell 144, 439-452. doi:10.1016/j.cell.2010.12.032

Borowiak, M., Maehr, R., Chen, S. et al. (2009). Small molecules efficiently direct endodermal differentiation of mouse and human embryonic stem cells. Cell Stem Cell 4, 348-358. doi:10.1016/j.stem.2009.01.014

Bruchmüller, I., Pirkl, E., Herrmann, R. et al. (2006). Introduction of a validation concept for a PCR-based Mycoplasma detection assay. Cytotherapy 8, 62-69. doi:10.1080/14653240500518413

Buehring, G. C., Eby, E. A. and Eby, M. J. (2004). Cell line cross-contamination: How aware are mammalian cell culturists of the problem and how to monitor it? In Vitro Cell Dev Biol Anim 40, 211-215. doi:10.1290/1543-706x(2004)40<211: clchaa $>2.0 . \operatorname{co} ; 2$

Burridge, P. W., Keller, G., Gold, J. D. et al. (2012). Production of de novo cardiomyocytes: Human pluripotent stem cell differentiation and direct reprogramming. Cell Stem Cell 10, 16-28. doi:10.1016/j.stem.2011.12.013

Buta, C., David, R., Dressel, R. et al. (2013). Reconsidering pluripotency tests: Do we still need teratoma assays? Stem Cell Res 11, 552-562. doi:10.1016/j.scr.2013.03.001

Chambers, S. M., Fasano, C. A., Papapetrou, E. P. et al. (2009). Highly efficient neural conversion of human ES and iPS cells by dual inhibition of SMAD signaling. Nat Biotechnol 27, 275-280. doi:10.1038/nbt.1529

Chi, K. R. (2013). Out, damned mycoplasma! Pointers for keeping your cell culture free of mycoplasma contamination. The Scientist. https://www.the-scientist.com/?articles.view/article No/38381/ (accessed 13.01.2021)

Christensen, K., Roudnicky, F., Patsch, C. et al. (2018). Requirements for using IPSC-based cell models for assay development in drug discovery. In Advances in Biochemical Engineering/Biotechnology (207-220). Springer Science and Business Media Deutschland GmbH. doi:10.1007/10_2017_23

Coecke, S., Balls, M., Bowe, G. et al. (2005). Guidance on good cell culture practice: A report of the second ECVAM task force on good cell culture practice. Altern to Lab Anim 33, 261-287. doi:10.1177/026119290503300313

Conrad, D. F., Pinto, D., Redon, R. et al. (2010). Origins and functional impact of copy number variation in the human genome. Nature 464, 704-712. doi:10.1038/nature08516

Crook, J. M., Tomaskovic-Crook, E. and Ludwig, T. E. (2017). Cryobanking pluripotent stem cells. Methods Mol Biol 1590, 151-164. doi:10.1007/978-1-4939-6921-0_11

D’Antonio, M., Woodruff, G., Nathanson, J. L. et al. (2017). High-throughput and cost-effective characterization of induced pluripotent stem cells. Stem Cell Reports 8, 1101-1111. doi:10.1016/j.stemcr.2017.03.011

de Miguel, M. P., Fuentes-Julián, S. and Alcaina, Y. (2010). Pluripotent stem cells: Origin, maintenance and induction. Stem Cell Rev Reports 6, 633-649. doi:10.1007/s12015-010-9170-1

Dekant, W. (2016). Toxicology and the reproducibility crisis: Scientific publishing, hazard assessment and risk characterization. Toxicol Lett 263, 76-77. doi:10.1016/j.toxlet.2016.09.001

Dirks, W. G., MacLeod, R. A. F., Nakamura, Y. et al. (2010). Cell line cross-contamination initiative: An interactive reference database of STR profiles covering common cancer cell lines. Int $J$ Cancer 126, 303-304. doi:10.1002/ijc.24999

Drexler, H. G. and Uphoff, C. C. (2002). Mycoplasma contamination of cell cultures: Incidence, sources, effects, detection, elimination, prevention. Cytotechnology 90, 75-90. doi:10.1023/A:1022913015916

Freedman, L. P., Gibson, M. C., Ethier, S. P. et al. (2015). Reproducibility: Changing the policies and culture of cell line authentication. Nat Methods 12, 493-497. doi:10.1038/nmeth.3403

Fritsche, E., Haarmann-Stemmann, T., Kapr, J. et al. (2020). Stem cells for next level toxicity testing in the $21^{\text {st }}$ century. Small 17 , e2006252. doi:10.1002/smll.202006252

Gertow, K., Przyborski, S., Loring, J. F. et al. (2007). Isolation of human embryonic stem cell-derived teratomas for the assessment of pluripotency. Curr Protoc Stem Cell Biol, Chapter 1, Unit1B.4. doi:10.1002/9780470151808.sc01b04s3

Gropp, M., Shilo, V., Vainer, G. et al. (2012). Standardization of the teratoma assay for analysis of pluripotency of human ES cells and biosafety of their differentiated progeny. PLoS One 7 , e45532. doi:10.1371/journal.pone.0045532

Hay, R. J., Macy, M. L. and Chen, T. R. (1989). Mycoplasma infection of cultured cells. Nature 339, 487-488. doi:10. 1038/339487a0

Hook, E. B. (1977). Exclusion of chromosomal mosaicism: Tables of $90 \%, 95 \%$, and $99 \%$ confidence limits and comments on use. Am J Hum Genet 29, 94-97.

Howe, B., Umrigar, A. and Tsien, F. (2014). Chromosome preparation from cultured cells. $J$ Vis Exp, 50203. doi:10.3791/50203

Hughes, P., Marshall, D., Reid, Y. et al. (2007). The costs of using unauthenticated, over-passaged cell lines: How much more data do we need? Biotechniques 43, 575-586. doi:10.2144/000112598

ISCBI (2009). Consensus guidance for banking and supply of human embryonic stem cell lines for research purposes. Stem Cell Rev Reports 5, 301-314. doi:10.1007/s12015-009-9085-x

ISCI (2018). Assessment of established techniques to determine de- 
velopmental and malignant potential of human pluripotent stem cells. Nat Commun 9, 1925. doi:10.1038/s41467-018-04011-3

ISCN (2016). An International System for Human Cytogenomic Nomenclature. J. McGowan-Jordan, A. Simons and M. Schmid (eds.). S. Karger AG. doi:10.1159/isbn.978-3-318-06861-0

Kattman, S. J., Witty, A. D., Gagliardi, M. et al. (2011). Stage-specific optimization of activin/nodal and BMP signaling promotes cardiac differentiation of mouse and human pluripotent stem cell lines. Cell Stem Cell 8, 228-240. doi:10.1016/j. stem.2010.12.008

Kilpinen, H., Goncalves, A., Leha, A. et al. (2017). Common genetic variation drives molecular heterogeneity in human iPSCs. Nature 546, 370-375. doi:10.1038/nature22403

Kim, J. H., Kurtz, A., Yuan, B. Z. et al. (2017). Report of the international stem cell banking initiative workshop activity: Current hurdles and progress in seed-stock banking of human pluripotent stem cells. Stem Cells Transl Med 6, 1956-1962. doi:10.1002/sctm.17-0144

Kim, J. H., Alderton, A., Crook, J. M. et al. (2019). A report from a workshop of the international stem cell banking initiative, held in collaboration of global alliance for iPSC therapies and the harvard stem cell institute, Boston, 2017. Stem Cells 37, 11301135. doi:10.1002/stem.3003

Kleensang, A., Vantangoli, M. M., Odwin-Dacosta, S. et al. (2016). Genetic variability in a frozen batch of MCF-7 cells invisible in routine authentication affecting cell function. Sci Rep 6, 28994. doi:10.1038/srep28994

Kurosawa, H. (2007). Methods for inducing embryoid body formation: In vitro differentiation system of embryonic stem cells. J Biosci Bioeng 103, 389-398. doi:10.1263/jbb.103.389

Langdon, S. P. (2004). Cell culture contamination: An overview. Methods Mol Med 88, 309-317. doi:10.1385/1-59259-406-9:309

Lei, M., Liang, D., Yang, Y. et al. (2020). Long-read DNA sequencing fully characterized chromothripsis in a patient with Langer-Giedion syndrome and Cornelia de Lange syndrome-4. J Hum Genet 65, 667-674. doi:10.1038/s10038-020-0754-6

Lenz, M., Goetzke, R., Schenk, A. et al. (2015). Epigenetic biomarker to support classification into pluripotent and non-pluripotent cells. Sci Rep 5, 8973. doi:10.1038/srep08973

Li, F., Hu, J., Xie, K. et al. (2015). Authentication of experimental materials: A remedy for the reproducibility crisis? Genes Dis 2, 283. doi:10.1016/j.gendis.2015.07.001

Liu, G., David, B. T., Trawczynski, M. et al. (2020). Advances in pluripotent stem cells: History, mechanisms, technologies, and applications. Stem Cell Rev Reports 16, 3-32. doi:10.1007/ s12015-019-09935-X

Liu, W. and Chen, G. (2014). Cryopreservation of human pluripotent stem cells in defined medium. Curr Protoc Stem Cell Biol 2014, 1c.17.1-1c.17.13. doi:10.1002/9780470151808. $\mathrm{sc} 01 \mathrm{c} 17 \mathrm{~s} 31$

Loring, J., Schwartz, P. and Wesselschmidt, R. (2007). Human Stem Cell Manual. $2^{\text {nd }}$ edition. San Siego, CA, USA: Academic Press.

Lorsch, J. R., Collins, F. S. and Lippincott-Schwartz, J. (2014). Fixing problems with cell lines. Science 346, 1452-1453. doi:10.1126/science. 1259110
MacArthur, D. G., Manolio, T. A., Dimmock, D. P. et al. (2014). Guidelines for investigating causality of sequence variants in human disease. Nature 508, 469-476. doi:10.1038/nature13127

MacLeod, R. A. F., Dirks, W. G., Matsuo, Y. et al. (1999). Widespread intraspecies cross-contamination of human tumor cell lines arising at source. Int J Cancer 83, 555-563. doi:10.1002/(SICI)1097-0215(19991112)83:4<555::AIDIJC19>3.0.CO;2-2

Maddah, M., Shoukat-Mumtaz, U., Nassirpour, S. et al. (2014). A system for automated, noninvasive, morphology-based evaluation of induced pluripotent stem cell cultures. J Lab Autom 19, 454-460. doi:10.1177/2211068214537258

Mayshar, Y., Ben-David, U., Lavon, N. et al. (2010). Identification and classification of chromosomal aberrations in human induced pluripotent stem cells. Cell Stem Cell 7, 521-531. doi:10.1016/j. stem.2010.07.017

McNutt, M. (2014). Journals unite for reproducibility. Science 346, 679. doi:10.1126/science.aaa1724

Miyakawa, T. (2020). No raw data, no science: Another possible source of the reproducibility crisis. Mol Brain 13, 24. doi:10. 1186/s13041-020-0552-2

Müller, F. J., Schuldt, B. M., Williams, R. et al. (2011). A bioinformatic assay for pluripotency in human cells. Nat Methods 8 , 315-317. doi:10.1038/nmeth. 1580

Müller, F.-J. (2014). Assessment of human pluripotent stem cells with PluriTest. StemBook. doi:10.3824/stembook.1.84.1

Munafò, M. R., Nosek, B. A., Bishop, D. V. M. et al. (2017). A manifesto for reproducible science. Nat Hum Behav 1, 0021. doi:10.1038/s41562-016-0021

Nelson-Rees, W. A., Daniels, D. W. and Flandermeyer, R. R. (1981). Cross-contamination of cells in culture. Science 212, 446-451. doi:10.1126/science.6451928

NIH (2015). NIH Workshop on Reproducibility in cell culture studies. https://videocast.nih.gov/watch_16876

Nikfarjam, L. and Farzaneh, P. (2012). Prevention and detection of mycoplasma contamination in cell culture. Cell J 13, 203-212.

Ntai, A., Baronchelli, S., La Spada, A. et al. (2017). A review of research-grade human induced pluripotent stem cells qualification and biobanking processes. Biopreserv Biobank 15, 384-392. doi:10.1089/bio.2016.0097

O'Shea, O., Steeg, R., Chapman, C. et al. (2020). Development and implementation of large-scale quality control for the European bank for induced pluripotent stem cells. Stem Cell Res 45, 101773. doi:10.1016/j.scr.2020.101773

OECD (2018). Guidance Document on Good In Vitro Method Practices (GIVIMP). OECD Series on Testing and Assessment, No. 286. OECD Publishing, Paris. doi:10.1787/9789264304796en

Pamies, D., Bal-Price, A., Simeonov, A. et al. (2017). Good cell culture practice for stem cells and stem-cell-derived models. ALTEX 34, 95-132. doi:10.14573/altex.1607121

Pamies, D., Bal-Price, A., Chesné, C. et al. (2018). Advanced good cell culture practice for human primary, stem cell-derived and organoid models as well as microphysiological systems. ALTEX 35, 353-378. doi:10.14573/altex.1710081

Pamies, D., Leist, M., Coecke, S. et al. (2020). Good cell and 
tissue culture practice 2.0 (GCCP 2.0) - Draft for stakeholder discussion and call for action. ALTEX 37, 490-492. doi:10.14573/ altex.2007091

Pistollato, F., Bremer-Hoffmann, S., Healy, L. et al. (2012). Standardization of pluripotent stem cell cultures for toxicity testing. Expert Opin Drug Metab Toxicol 8, 239-257. doi:10.1517/1742 5255.2012 .639763

Rohani, L., Johnson, A. A., Naghsh, P. et al. (2018). Concise review: Molecular cytogenetics and quality control: Clinical guardians for pluripotent stem cells. Stem Cells Transl Med 7, 867-875. doi:10.1002/sctm.18-0087

Rojas, A., Gonzalez, I. and Figueroa, H. (2008). Cell line cross-contamination in biomedical research: A call to prevent unawareness. Acta Pharmacol Sin 29, 877-880. doi:10.1111/ j.1745-7254.2008.00809.x

Rottem, S. and Barile, M. F. (1993). Beware of mycoplasmas. Trends Biotechnol 11, 143-151. doi:10.1016/01677799(93)90089-R

Sarafian, R., Morato-Marques, M., Borsoi, J. et al. (2018). Monitoring cell line identity in collections of human induced pluripotent stem cells. Stem Cell Res 28, 66-70. doi:10.1016/j. scr.2018.01.030

Sathananthan, A. H. and Trounson, A. (2005). Human embryonic stem cells and their spontaneous differentation. Ital J Anat Embryol 110, Suppl, 151-157.

Scudellari, M. (2016). A decade of : iPS Cells. Nature 534, 310312. doi:10.1038/534310a

Shibamiya, A., Schulze, E., Krauß, D. et al. (2020). Cell banking of hiPSCs: A practical guide to cryopreservation and quality control in basic research. Curr Protoc Stem Cell Biol 55, e127. doi:10.1002/cpsc. 127

Sikkema-Raddatz, B., Castedo, S. and Te Meerman, G. J. (1997). Probability tables for exclusion of mosaicism in prenatal diagnosis. Prenat Diagn 17, 115-118. doi:10.1002/(SICI)10970223(199702)17:2<115::AID-PD37>3.0.CO;2-A

Stacey, G. N., Crook, J. M., Hei, D. et al. (2013). Banking human induced pluripotent stem cells: Lessons learned from embryonic stem cells? Cell Stem Cell 13, 385-388. doi:10.1016/j. stem.2013.09.007

Stacey, G. N., Masters, J. R. W., Hay, R. J. et al. (2000). Cell contamination leads to inaccurate data: We must take action now. Nature 403, 356. doi:10.1038/35000394

Sullivan, S., Stacey, G. N., Akazawa, C. et al. (2018). Quality control guidelines for clinical-grade human induced pluripotent stem cell lines. Regen Med 13, 859-866. doi:10.2217/rme-20180095

Suter-Dick, L., Alves, P. M., Blaauboer, B. J. et al. (2015). Stem cell-derived systems in toxicology assessment. Stem Cells Dev 24, 1284-1296. doi:10.1089/scd.2014.0540

Taapken, S. M., Nisler, B. S., Newton, M. A. et al. (2011). Karotypic abnormalities in human induced pluripotent stem cells and embryonic stem cells. Nat Biotechnol 29, 313-314. doi:10.1038/ nbt. 1835

Takahashi, K., Tanabe, K., Ohnuki, M. et al. (2007). Induction of pluripotent stem cells from adult human fibroblasts by defined factors. Cell 131, 861-872. doi:10.1016/j.cell.2007.11.019

Timenetsky, J., Santos, L. M., Buzinhani, M. et al. (2006). Detection of multiple mycoplasma infection in cell cultures by PCR. Brazilian J Med Biol Res 39, 907-914. doi:10.1590/S0100879X2006000700009

Wagner, K. and Welch, D. (2010). Cryopreserving and recovering of human iPS cells using complete knockout serum replacement feeder-free medium. $J$ Vis Exp, e2237. doi:10.3791/2237

Wakui, T. (2017). Method for evaluation of human induced pluripotent stem cell quality using image analysis based on the biological morphology of cells. J Med Imaging 4, 1. doi:10.1117/1. jmi.4.4.044003

WHO (2013). Annex 3. Recommendations for the evaluation of animal cell cultures as substrates for the manufacture of biological medicinal products and for the characterization of cell banks. Replacement of Annex 1 of WHO Technical Report Series, No. 878. http://www.who.int/biologicals/vaccines/TRS_978_ Annex_3.pdf(accessed 13.01.2021)

Xu, H., Baroukh, C., Dannenfelser, R. et al. (2013). ESCAPE: Database for integrating high-content published data collected from human and mouse embryonic stem cells. Database 2013, bat045. doi:10.1093/database/bat045

Yaffe, M. P., Noggle, S. A. and Solomon, S. L. (2016). Raising the standards of stem cell line quality. Nat Cell Biol 18, 236-237. doi: $10.1038 /$ ncb3313

Yu, M., Selvaraj, S. K., Liang-Chu, M. M. Y. et al. (2015). A resource for cell line authentication, annotation and quality control. Nature 520, 307-311. doi:10.1038/nature14397

Zhang, S., Liang, F., Lei, C. et al. (2019). Long-read sequencing and haplotype linkage analysis enabled preimplantation genetic testing for patients carrying pathogenic inversions. J Med Genet 56, 741-749. doi:10.1136/jmedgenet-2018-105976

\section{Conflict of interest}

The authors have no conflicts of interest.

\section{Acknowledgements}

The authors thank Dr Petra Boehme (Institute for Forensic Medicine, UKD), Dr Sebastian Hänsch (CAi, HHU Düsseldorf), and Kirstin K. Melton (Thermo Fischer Scientific) for excellent technical support. The graphical abstract and Figure 1 were created using BioRender.com. This work was supported by the project CERST (Center for Alternatives to Animal Testing) of the Ministry for Culture and Science of the State of North-Rhine Westphalia, Germany [file number 233-1.08.03.03-121972/131 1.08.03.03 - 121972], the European Union's Horizon 2020 Research and Innovation Program, ENDpoiNTs project [grant agreement number: 825759], the DisCoVer VIP+ project of the Federal Ministry of Education and Research [BMBF; funding code: 03VP03792], and a project of the Leibniz Cooperative Excellence program [application number K246/2019]. 